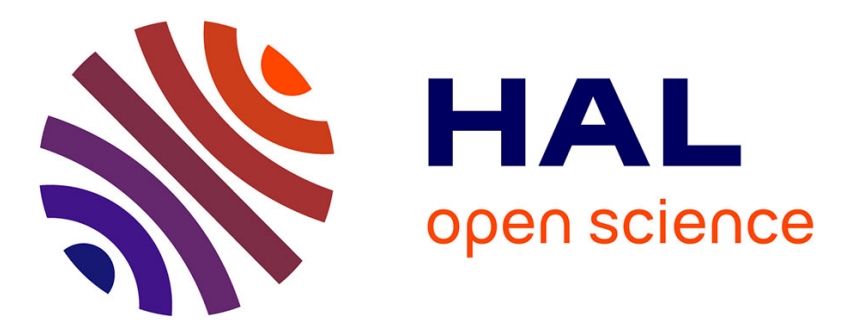

\title{
Impact of spatial resolution on simulated surface water mass transformations in the Atlantic
}

Sergei K. Gulev, Bernard Barnier, Jean-Marc Molines, Thierry Penduff, Jérôme Chanut

\section{- To cite this version:}

Sergei K. Gulev, Bernard Barnier, Jean-Marc Molines, Thierry Penduff, Jérôme Chanut. Impact of spatial resolution on simulated surface water mass transformations in the Atlantic. Ocean Modelling, 2007, 19, pp.138-160. 10.1016/j.ocemod.2007.07.004 . hal-00270761

\section{HAL Id: hal-00270761 \\ https://hal.science/hal-00270761}

Submitted on 13 Feb 2020

HAL is a multi-disciplinary open access archive for the deposit and dissemination of scientific research documents, whether they are published or not. The documents may come from teaching and research institutions in France or abroad, or from public or private research centers.
L'archive ouverte pluridisciplinaire HAL, est destinée au dépôt et à la diffusion de documents scientifiques de niveau recherche, publiés ou non, émanant des établissements d'enseignement et de recherche français ou étrangers, des laboratoires publics ou privés.

\section{(c)(1)}

Distributed under a Creative Commons Attribution| 4.0 International License 


\title{
Impact of spatial resolution on simulated surface water mass transformations in the Atlantic
}

\author{
Sergey K. Gulev ${ }^{\mathrm{a}, *}$, Bernard Barnier ${ }^{\mathrm{b}}$, Jean-Marc Molines ${ }^{\mathrm{b}}$, \\ Thierry Penduff ${ }^{\mathrm{b}}$, Jérôme Chanut ${ }^{\mathrm{c}}$ \\ ${ }^{a}$ P.P. Shirshov Institute of Oceanology, RAS, 36 Nakhimovsky Avenue, 117851 Moscow, Russia \\ ${ }^{\mathrm{b}}$ Laboratoire des Ecoulements Géophysiques et Industriels, Grenoble, France \\ 'MERCATOR-Oce'an, Toulouse, France
}

\begin{abstract}
We analyze the water mass transformation in coarse $\left(1^{\circ}\right)$ and high $\left(1 / 6^{\circ}\right)$ resolution ocean simulations with the identical configuration of the CLIPPER model and interannual ERA15 forcing function. Climatological characteristics of surface water mass transformation in the two experiments are quite different. The high resolution experiment exhibits a stronger surface transformation in equatorial and tropical regions, in the Gulf Stream area and in the location of the formation of Subtropical Mode Water (STMW), associated with high levels of eddy kinetic energy. The coarse resolution experiment shows a better representation of the transformation rates corresponding to the densest subpolar mode waters and Labrador Sea Water (LSW). This is explained by the differences in lateral mixing procedures between high and coarse resolution experiments. The high resolution $1 / 6^{\circ}$ run is eddy-resolving only in the tropics and mid-latitudes. In these areas eddies are found to enhance the process of water mass transformation compared to the isopycnal diffusion used to parameterized the eddies in the $1^{\circ}$ model. Despite its $1 / 6^{\circ}$ resolution, the high resolution model does not adequately represent eddies in the subpolar gyre and Labrador Sea. In these areas the high resolution model fails to correctly simulate water mass transformation because the lateral mixing (provided through the bi-harmonic sub-gridscale parameterization) of newly ventilated waters with surrounding waters is not efficient enough. In contrast in the coarse $1^{\circ}$ resolution model, the strong lateral mixing and the unrealistically broad boundary currents imposed by the high diffusivity required for numerical stability mixes newly formed LSW waters with the warmer and saltier waters of the rim current. Finally, it results in a more effective representation of the surface water mass transformation in high latitudes in the $1^{\circ}$ model. A possible impact of the increased lateral diffusion in high resolution experiment on the representation of re-stratification in the Labrador Sea was studied in sensitivity experiments with different lateral diffusion coefficients compared to the regional eddy-resolving $1 / 15^{\circ}$ simulation in the subpolar North Atlantic. If the eddies are not resolved in subpolar latitudes (as in the case of $1 / 6^{\circ}$ model), the GM90 parameterization with the coefficient close to $800 \mathrm{~m}^{2} \mathrm{~s}^{-1}$ provides the closest agreement with the solution of eddy-resolving $1 / 15^{\circ}$ model.
\end{abstract}

\footnotetext{
* Corresponding author. Tel.: +7 095 1247985; fax: +7 0951245983.

E-mail address: gul@sail.msk.ru (S.K.Gulev).
} 


\section{Introduction}

The surface water mass transformation rate represents an integral measure of the impact of surface heat and fresh water fluxes on the ocean circulation, combining the thermal and haline contributions to the buoyancy fluxes. Starting from a pioneering work of Walin (1982), surface water mass transformation was diagnosed for different oceanic domains using different surface flux data sets (e.g. Tziperman, 1986; Schmitt et al., 1989; Speer and Tziperman, 1992; Speer, 1993; Speer et al., 1995; Marshall et al., 1999; Marsh, 2000; Large and Nurser, 2001). During the last decade global sea-air flux climatologies became available from the voluntary observing ship (VOS) data (da Silva et al., 1994; Josey et al., 1999) and from meteorological reanalyses (Kalnay et al., 1996; Kistler et al., 2001; Uppala et al., 2005). This initiated a number of numerical simulations with ocean general circulation models (OGCMs) for periods of several decades, in attempts to reproduce the observed climate variability in the ocean (Battisti et al., 1995; Halliwell, 1998; Visbeck et al., 1998; Hakkinen, 1999; Ezer, 1999; Eden and Willebrand, 2001; Krahmann et al., 2001; Gulev et al., 2003; Beismann and Barnier, 2004; Marsh et al., 2005). Analysis of surface water mass transformation in such model experiments can help to understand the role of buoyancy forcing in driving the ocean circulation. Nurser et al. (1999) first diagnosed water mass transformation in the North Atlantic with an isopycnic coordinate OGCM and quantified the differences between the density fluxes implied by the surface forcing and those actually diagnosed by the model, which uses the relaxation to the surface temperature and salinity as a surface forcing formulation. Ladd and Thompson (2001) used an isopycnal model to analyze the formation of major mode waters in the North Pacific. Gulev et al. (2003) have shown that surface water mass transformation can be effectively used for the analysis of the mechanisms of interannual to decadal scale variability in the North Atlantic as simulated by the SPEM model (sigma-coordinate primitive equation model; Haidvogel et al., 1991). They found that the North Atlantic water mass transformation variability is associated with the North Atlantic Oscillation (NAO) signatures in surface fluxes. Recently Haines and Old (2005) analysed North Atlantic water mass transformation in the HadCM3 climate model and also found it to be closely linked to the NAO variability.

Most of the above cited model experiments were done with relatively coarse resolution OGCMs (1-2 degree). High resolution, eddy-resolving ocean modeling is known to improve considerably many of the basic circulation characteristics (e.g. Böning and Budich, 1992; Böning et al., 1996; Griffies et al., 2000; Barnier et al., 2006). Marsh et al. (2005) analysed water mass transformation in an eddy-permitting $1 / 4^{\circ}$ resolution Ocean Circulation and Climate Advanced Model (OCCAM) forced by surface turbulent fluxes, derived from NCEP/NCAR surface variables as recommended by Large et al. (1997), in combination with ISCCP radiative fluxes (Bishop and Rossow, 1991). In general, it is obvious that such processes as deep convection in the Labrador Sea, responsible for the formation of the Labrador Sea water (LSW), formation of the Subtropical Mode Waters (STMW) in the re-circulation of Gulf Stream and thermocline ventilation through the detrainment of surface waters into the thermocline have a synoptic-scale nature and should be more adequately represented using high resolution models (Chanut et al., submitted for publication). However, the above cited studies with high and coarse resolution models can hardly be compared with each other due to very different model formulations and forcing functions used.

In the present work we diagnose surface water mass transformation in the Atlantic OGCM CLIPPER (Treguier et al., 2001), which was ran in the same configuration at both coarse $\left(1^{\circ}\right)$ and high $\left(1 / 6^{\circ}\right)$ resolutions, with the same unique formulation of forcing. Recently Valdivieso Da Costa et al. (2005) analysed subduction rates, along with the surface water mass transformation rates in the high resolution, $1 / 6^{\circ}$, CLIPPER simulation forced by a repeated annual cycle of fluxes from ERA-15 reanalysis. They pointed out the critical importance of mesoscale eddies in the formation rates, and found that the $1 / 6^{\circ}$ CLIPPER model diagnoses somewhat different structure of transformation rates from earlier diagnostic based on observations (Speer and Tziperman, 1992) and from coarse resolution $\left(1^{\circ}\right)$ experiment with SPEM (Gulev et al., 2003).

The objective of this study is to quantify the effect of grid resolution on the characteristics of surface water mass transformation by comparing the results from the CLIPPER simulations at coarse $\left(1^{\circ}\right)$ and high $\left(1 / 6^{\circ}\right)$ resolution. Since at $1 / 6^{\circ}$ resolution, the CLIPPER model is eddy-resolving only at latitudes between $50^{\circ} \mathrm{S}$ and $50^{\circ} \mathrm{N}$ (see Table 1), differences observed between $1^{\circ}$ and $1 / 6^{\circ}$ resolutions can be interpreted in terms of eddy effects in this band of latitude only. At subpolar latitudes (in particular in the Labrador Sea) where neither the 
Table 1

Comparison of ATL6 and ATL1 grid resolution to the local first radius of deformation (after Chelton et al., 1998) at selected latitudes

\begin{tabular}{lllll}
\hline Latitude & ATL6 $1 / 6^{\circ}$ resolution $(\mathrm{km})$ & ATL1 $1^{\circ}$ resolution $(\mathrm{km})$ & First baroclinic Rossby radius $(\mathrm{km})$ & Dominant lateral mixing \\
\hline Equator & 18.5 & 111.0 & 230 & $\begin{array}{l}\text { ATL6: Resolved eddies } \\
\text { ATL1: Isopycnal Laplacian }\end{array}$ \\
$20^{\circ} \mathrm{N}$ & 17.3 & 103.8 & 55 & $\begin{array}{l}\text { ATL6: Resolved eddies } \\
\text { ATL1: Isopycnal Laplacian }\end{array}$ \\
$45^{\circ} \mathrm{N}$ & 13.0 & 78.0 & 30 & $\begin{array}{l}\text { ATL6: Resolved eddies } \\
\text { ATL1: Isopycnal Laplacian }\end{array}$ \\
$60^{\circ} \mathrm{N}$ & 9.3 & & & ATL6: Horizontal bi-harmonic \\
& & 55.5 & 10 & ATL1: Isopycnal Laplacian \\
\hline
\end{tabular}

The process dominating the lateral mixing of tracers in the various simulations is indicated.

$1^{\circ}$ nor $1 / 6^{\circ}$ resolutions allow for eddies, differences between the various CLIPPER simulations will be attributed to sub-gridscale parameterization effects. Section 2 describes briefly the CLIPPER model configuration and forcing formulation. Comparative assessments of the mean characteristics of surface water mass transformation in the high and coarse resolution simulations are given in Section 3. In Section 4 we discuss the results in the context of the role of synoptic eddies in the ocean circulation.

\section{Model configurations, forcing formulation and large scale solutions}

We use the results of two 15-year interannual simulations carried out with the CLIPPER model, which only differ by the horizontal grid resolution. This model is an implementation in the Atlantic of the OPA8.1 numerical ocean GCM (Madec et al., 1998). OPA solves the three-dimensional primitive equations in spherical coordinates discretized on a $\mathrm{C}$-grid and fixed vertical levels ( $z$-coordinate), assuming hydrostatic equilibrium, the Boussinesq and rigid lid approximations. The vertical mixing (including the surface mixed layer) is parameterized according to a second-order turbulent eddy kinetic energy closure algorithm. In case of static instability, viscosity/diffusivity enhancement of $1 \mathrm{~m}^{2} \mathrm{~s}^{-1}$ is used.

The model domain covers the Atlantic from $70^{\circ} \mathrm{N}$ to $75^{\circ} \mathrm{S}$, and is discretized on a Mercator isotropic longitude $\times$ latitude grid, and 43 vertical levels (Treguier et al., 2001). The high resolution simulation, ATL6 hereafter, uses a resolution of $1 / 6^{\circ} \times 1 / 6^{\circ} \cos \phi(\phi$ being latitude). In the coarse resolution simulation, ATL1 hereafter, the resolution is six time coarser $\left(1^{\circ} \times 1^{\circ} \cos \phi\right)$. Although the model domain covers the whole Atlantic, the focus of this study is on the water mass transformation in the North Atlantic from $20^{\circ} \mathrm{S}$ to $70^{\circ} \mathrm{N}$. As shown in Table 1, ATL6 can be considered as eddy-resolving only up to at most $50^{\circ}$ (where its grid resolution is still half of the 1st deformation radius), and it is clearly not resolving eddies in the subpolar gyre (where its grid resolution is of the order the 1st deformation radius).

Details of the CLIPPER model configuration and spin-up are described in Treguier et al. (2001) and Valdivieso Da Costa et al. (2005). The model has open boundaries at the strait of Gibraltar, in the southern ocean at Drake Passage and south of Africa. The algorithm described in Treguier et al. (2001) is used at these open boundaries. At $70^{\circ} \mathrm{N}$ the model uses a combination of open boundary conditions with the relaxation to the Reynaud et al. (1998) climatology. The parameterization of lateral mixing in ATL6 is a horizontal bi-harmonic operator for tracers and momentum. The mixing coefficient varies with latitude as $A_{4} \times(\cos \phi)^{3}$, with $A_{4}=5 \times 10^{-11} \mathrm{~m}^{4} \mathrm{~s}^{-1}$, a decrease proportional to the third power of the grid spacing, as in the DYNAMO model intercomparison experiment (Willebrand et al., 2001). In the coarse resolution simulation ATL1, lateral mixing of tracers (momentum) is provided by isopycnal (horizontal) laplacian diffusivity which decreases with the grid spacing as $A_{2} \times(\cos \phi)$, with $A_{2}=2000 \mathrm{~m}^{2} \mathrm{~s}^{-1}$ for tracers and $A_{2}=5000 \mathrm{~m}^{2} \mathrm{~s}^{-1}$ for momentum. Further details on model configuration can be found in Treguier et al. (2001), or in Beismann and Barnier (2004) for ATL1 and Penduff et al. (2005) for ATL6.

The model is forced by the surface heat, freshwater and momentum fluxes from ERA15, the European Centre for Medium Range Weather Forecasts (ECMWF) reanalysis, spanning the period 1979-1993. Detailed evaluation of this forcing function can be found in the WGASF Group (2000) and Garnier et al. (2000). The surface forcing in the model was applied according to Barnier et al. (1995) and Barnier (1998). Being a 
development of the surface boundary conditions of Haney (1971), this formulation considers the feedback of the ocean to the atmosphere and gives the model a much higher degree of freedom (allowing in particular a prognostic meridional heat transport). It was successfully used in the experiments with the SPEM model (Gulev et al., 2003) and in many other numerical experiments. In this formulation the surface heat flux applied at a time $t$ as surface boundary condition of the temperature equation, $Q_{\text {net }}(t)$, is formulated as

$$
Q_{\mathrm{net}}(t)=Q_{\mathrm{net}}^{\prime}(t)-\frac{\partial Q}{\partial T}\left(\operatorname{SST}(t)-T_{S}(t)\right)
$$

$Q_{\text {net }}^{\prime}(t)$ is the net surface heat flux from ERA15 at this time. $\partial Q / \partial T$ is the feedback term (Barnier et al., 1995), represented by spatially varying climatological monthly mean values. According to Barnier et al. (1995) $\partial Q / \partial T$ varies from 30 to $55 \mathrm{~W} / \mathrm{m}^{2} \mathrm{~K}^{-1}$ with the largest values identified in the Gulfstream area in winter and in the western Atlantic tropics in summer. SST $(t)$ and $T_{S}(t)$ represent respectively the Reynolds SST (Reynolds and Smith, 1994) and the surface temperature calculated by the model at this time. If the feedback term was expressed as a time relaxation to an "equivalent" observed SST, it would typically vary from 45 days in the Gulf Stream area to 60-75 days in the open ocean regions. The salinity equation is forced by a virtual salt flux (Barnier, 1998), proportional to a freshwater flux, $(E-P)(t)$ which reflects the freshwater budget at time $t$ :

$$
(E-P)(t)=(E(t)-P(t)-R(t))+\frac{\Delta z}{\tau}\left(\frac{\operatorname{SSS}(t)-S_{S}(t)}{S_{S}(t)}\right)
$$

where $E(t)$ is evaporation and $P(t)$ is precipitation, both taken from ERA15 at time $t, R(t)$ is the river runoff, $S_{\mathrm{s}}(t)$ is the surface salinity calculated by the model at time $t, \tau$ is a relaxation time and $\Delta z$ is the thickness of the first model layer. SSS $(t)$ should be equivalent to the observational sea surface salinity at the same time $t$. We used in (2) the climatic seasonal estimates from the climatology of Reynaud et al. (1998) interpolated at time $t$. The relaxation time scale $\tau$ was set to the relaxation time for temperature. A climatological value of the river runoff $R(t)$ in (2) has been added at a few grid points next to the main river estuaries. The sea ice parameterization sets the surface flux to zero and applies a 3-day relaxation of the model SST to the freezing temperature and of the model SSS to the climatic SSS (Reynaud et al., 1998), when the observed surface temperature falls below $-1.8{ }^{\circ} \mathrm{C}$. The momentum equation was forced by the ERA15 wind stress as surface boundary condition. The model has been forced by daily values of forcing components, which were linearly interpolated to the model time steps.

Both interannual simulations ATL1 and ATL6 are spun-up from rest for 8 years, using the $T, S$ climatology of Reynaud et al. (1998) as initial conditions, and the 15-year climatological seasonal cycle of ERA-15 fluxes as forcing. The mean state at the end of the spin-up represents well the major circulation features in the Atlantic. The maximum of the meridional overturning circulation (MOC) in its usual depth-latitude representation (not shown) is about $16 \mathrm{~Sv}$ at $48^{\circ} \mathrm{N}$ and $1200 \mathrm{~m}$ depth in ATL6. In ATL1, the MOC maximum is $14 \mathrm{~Sv}$ at $45^{\circ} \mathrm{N}$.

The meridional overturning streamfunction is shown in a density coordinate representation in Fig. 1 . This representation includes the influence of horizontal gyres in the cases when their northward and southward branches have different densities. It confirms the stronger meridional circulation at $1 / 6^{\circ}$. At $30^{\circ} \mathrm{S}$, the upper branch (northward) of the MOC is principally made of waters of density comprised between 26 and 27 ( $10 \mathrm{~Sv}$ of those, against $6 \mathrm{~Sv}$ in ATL1). These waters of Southern Hemisphere origin are feeding the equatorial upwelling. The contribution of the shallow subtropical cell to the equatorial upwelling (through $\sigma_{0}=24$ ) is $4 \mathrm{~Sv}$ greater in ATL1, compensating for the deficit of southern hemisphere waters. Waters cross the equator at lighter density in $1 / 6^{\circ}$ simulation, the volume of water lighter than $\sigma_{0}=23$ crossing the equator being significantly greater in ATL6 (the contribution of the Amazon river outflow parameterization is crucial here). When they reach the latitude of the Gulf Stream separation (around $36^{\circ} \mathrm{N}$ ), these waters have been made denser than 24 in both simulations. The transformation to subpolar density along the path of the Gulf Stream and the North Atlantic Current occurs in a smaller band of latitude $\left(36^{\circ} \mathrm{N}\right.$ to $\left.50^{\circ} \mathrm{N}\right)$ in ATL6 due to sharper fronts (it extends to $55^{\circ} \mathrm{N}$ in ATL1). Connection with the dense return branch of the MOC is localized at $60^{\circ} \mathrm{N}$ in ATL1, being more spread in ATL6 between 60 and $65^{\circ} \mathrm{N}$. Overflows are $2 \mathrm{~Sv}$ stronger at $1 / 6^{\circ}$ simulation which accounts for the greater maximum at $55^{\circ} \mathrm{N}$ ( $14 \mathrm{~Sv}$ against 12 in ATL1). The gradual erosion of the 

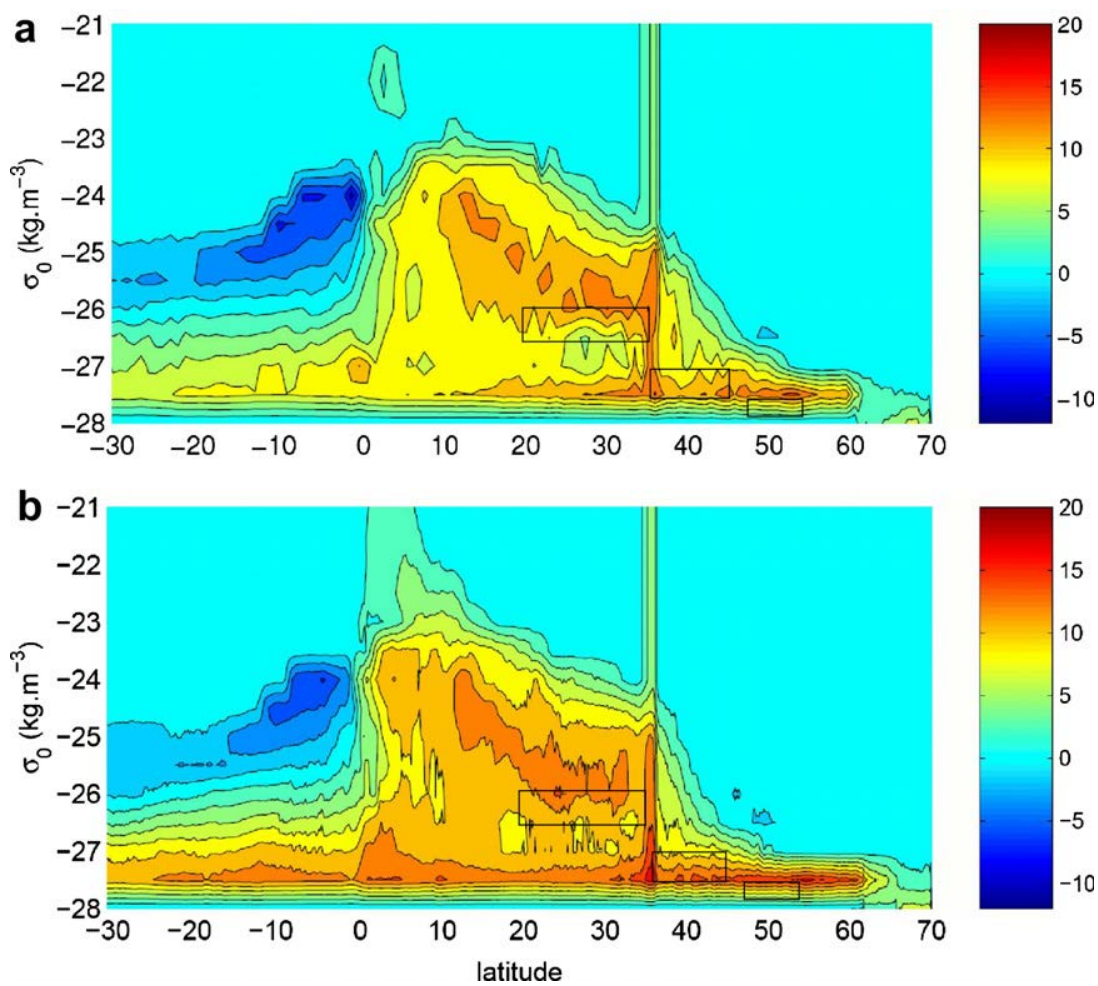

Fig. 1. Meridional overturning streamfunction, represented in latitude-potential density $\left(\sigma_{0}\right)$ coordinates for ATL1 (a) and ATL6 (b) experiments. Contour interval is $2 \mathrm{~Sv}$. The discontinuity at $36^{\circ} \mathrm{N}$ must be ignored since it is an artefact induced by not accounting for the flow through the open boundary in the Gulf of Cadiz in the calculation of the streamfunction. Rectangles indicate the depth and density ranges where the contribution of surface forced overturning shown in Fig. 9 is maximum (see text).

lower branch of the MOC as the Deep Western Boundary Current flows south is more pronounced in ATL1 where $6 \mathrm{~Sv}$ are lost by diapycnal mixing between $55^{\circ} \mathrm{N}$ and $30^{\circ} \mathrm{S}$ against $4 \mathrm{~Sv}$ at $1 / 6^{\circ}$.

The advective meridional heat transport (MHT) is generally $0.1-0.2 \mathrm{PW}$ smaller in ATL1, but both reach their maximum at $18^{\circ} \mathrm{N}(0.95 \mathrm{PW}$ in ATL6 and $0.8 \mathrm{PW}$ in ATL1). The behavior of the MHT at subtropical and subpolar latitudes is somewhat different in the two experiments, reflecting the contribution of eddy transport to MHT in ATL6 and a weak divergence of the heat flux in the mid-latitudes in ATL1, which is typical for many coarse resolution simulations (e.g. Gulev et al., 2003).

The present model solutions in both experiments show the separation of the Gulf-Stream somewhat northward from Cape Hatteras, as in most $z$-coordinate models (Treguier et al., 2001; Valdivieso Da Costa et al., 2005). The location of the North Atlantic current (NAC) in the open Atlantic also somewhat disagrees with observations, showing a southward shift in the Eastern Atlantic. Nevertheless, the magnitude of the eddy kinetic energy (EKE), at least south of $50^{\circ} \mathrm{N}$, agrees with observations quite well (Penduff et al., 2004; Valdivieso Da Costa et al., 2005). The water mass analysis in the model (CLIPPER Team, 2001) showed reliable representation of the major mode waters in the North and South Atlantic. One known problem of ATL6 is the simulation of the mixed layer depth (MLD) in the Labrador Sea, because at these latitudes, even $1 / 6^{\circ}$ resolution does not guarantee an adequate representation of convection/re-stratification processes (Chanut et al., submitted for publication). However this does not imply necessarily wrong representation of surface water mass transformation, even in this area. The largest model drift was identified at depths 400-700 $\mathrm{m}$ and was quite similar in both experiments. However, surface quantities were just slightly affected by the drift, mostly in the equatorial region. Further details of the spin-up experiments are given in Treguier et al. (2001), CLIPPER Team (2001), Penduff et al. (2004) and Valdivieso Da Costa et al. (2005).

After the spin-up phase, both simulations have been continued, being forced from 1979 to 1993 by ERA15 fluxes applied as specified above. Reynolds SST is available at weekly resolution (OI version) starting from 

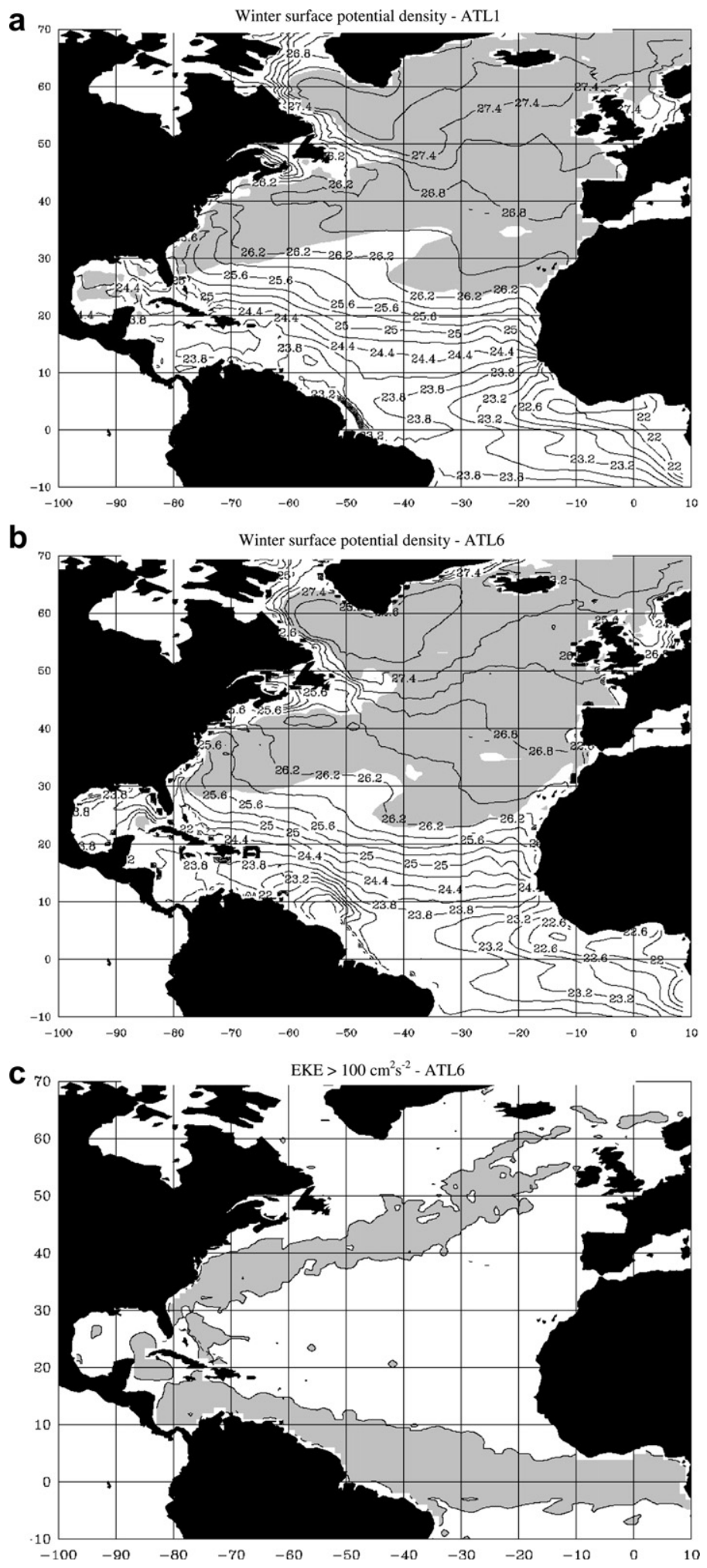

Fig. 2. Mean (1982-1993 average) winter (JFM) maps of surface density in the experiments ATL1 (a) and ATL6 (b). The area where the winter MLD is deeper than $100 \mathrm{~m}$ is shaded by grey. Regions where EKE values are greater than $100 \mathrm{~cm}^{2} / \mathrm{s}^{2}$ in ATL6 are shown in grey in (c). 
1982. Thus for the period 1979-1981, monthly Reynolds SST was used. In order to avoid the impacts of such temporal inhomogeneities in the forcing functions (change of monthly SST to weekly SST) we only use 12 years of the experiment (1982-1993), which were forced by the homogeneous surface forcing. Weekly SST was interpolated daily, and daily values of ERA15 surface fluxes were computed from the original 6-h values. In order to better account for the synoptic features of ocean circulation, the CLIPPER project used a 5-day storage strategy, in which the snapshots were averaged over 5-day periods (Crosnier et al., 2001).

Circulation characteristics of both high and coarse resolution versions of CLIPPER model were analysed in a number of studies. The CLIPPER model at $1^{\circ}$ resolution was used by Beismann and Barnier (2004) for studying Atlantic interannual variability. Diagnostics of the circulation characteristics of the ATL6 experiment was presented in Treguier et al. (2001, 2003). Hall et al. (2004) have analysed interannual variability in heat transport across the Gulf Stream in ATL6 and found two sources of variability: one is a response to the wind stress variability and is linked with the North Atlantic Oscillation (NAO); the other, independent of the surface forcing, is associated with internally generated transient oceanic disturbances. Detailed analysis of interannual variability in the ATL6 associated with NAO was also performed by Penduff et al. (2004). However, the water mass transformation characteristics were not yet comprehensively assessed in CLIPPER.

Since the water mass transformation strongly depends on the ocean surface density, especially in winter (JFM), we have plotted in Fig. 2 the mean winter maps of the surface density in ATL1 and ATL6. These maps are qualitatively comparable to those presented in other model studies (Nurser et al., 1999; or Ladd and Thompson, 2001). At large scale, the winter outcropping lines of density surfaces appear similar in both experiments. In particular, both locate the band $27.0<\sigma_{0}<27.2$ nearly along $50^{\circ} \mathrm{N}$, so the density of $\sigma_{0}=27$ will be chosen in the following as reference density to separate between subpolar and subtropical latitudes (and in ATL6 between eddy-resolving and non-eddy resolving regions). Significant differences between ATL1 and ATL6 are found in the region of the western equatorial Atlantic influenced by the Amazon River runoff (which has a much greater off-shore extent in ATL6), and along the Gulf-Stream path (waters are significantly lighter in ATL6 in the early part of the path between $80^{\circ} \mathrm{W}$ and $60^{\circ} \mathrm{W}$ ), two regions of strong currents and high eddy kinetic energy in ATL6 (Fig. 2c).

\section{Surface water mass transformation in simulations of different spatial resolution}

\subsection{Surface density fluxes in ATL1 and ATL6}

The density flux, $f$, which determines the changes in buoyancy at the surface is calculated using the formula proposed in a number of works (e.g. Speer and Tziperman, 1992; Large and Nurser, 2001; Gulev et al., 2003):

$$
f=\frac{-\alpha}{C_{P}} Q_{\text {net }}+\rho_{0} \beta \frac{(E-P) S}{1-S},
$$

where $C_{P}$ is specific heat of sea water at constant pressure, $\rho_{0}$ is a reference density of sea water, $s$ is salinity in portions of unity, $\alpha$ and $\beta$ are the thermal expansion and haline contraction coefficients:

$$
\alpha=\partial \rho / \rho \partial T, \quad \beta=\partial \rho / \rho \partial S .
$$

Surface density $\rho$ was computed at each snapshot, using the equation of state used in the CLIPPER model (after Jackett and McDougall, 1995). In the rhs of (3), the first (second) term represents the thermal (haline) component of the total density flux (or density flux). It is often informative to look at each component separately. Note that the density flux is named so when the positive sign is attributed to the fluxes from the ocean to the atmosphere, but is named buoyancy flux when an opposite definition of the sign is used.

In this study, we qualify by original the surface density flux calculated from the original ERA15 net heat and fresh water fluxes, i.e. without including the feedback terms implied by (1) and (2). We shall qualify as actual density flux the surface density flux calculated from the fluxes diagnosed by the model, i.e. ERA15 fluxes corrected by the retroaction terms (1) and (2). Note that original density fluxes will not be identical in ATL6 and ATL1 although they are calculated from the same original net heat and freshwater fluxes. We expect that differences in surface temperature and salinity between the models will induce deviations in the calculation of $f$ through their influence on the expansion coefficients $\alpha$ and $\beta$ and the freshwater contribution which explicitly 
depends on the model salinity $S$ (Eq. (3)). Greater differences are expected between the actual density fluxes, since the feedback terms will, in addition, induce deviations in the net heat and freshwater fluxes used in (3).

Fig. 3a shows the 12-year mean original surface density flux for ATL6. Large positive values of the original density flux (generation of denser water) with the maximum of $12 \times 10^{-6} \mathrm{~kg} \mathrm{~m}^{-2} \mathrm{~s}^{-1}$ are observed over the Gulf Stream path and the NAC. Tropical (between $10^{\circ} \mathrm{N}$ and $30^{\circ} \mathrm{N}$ ) maxima are characterized by the values 4-6 $\times 10^{-6} \mathrm{~kg} \mathrm{~m}^{-2} \mathrm{~s}^{-1}$. In the Labrador Sea, ERA15 fluxes diagnose approximately half the size of positive density fluxes in comparison to those diagnosed by the SPEM model (Gulev et al., 2003) using the NCEP/ NCAR reanalysis. The most intensive negative density flux (generation of lighter water) is found in the equatorial and the southeast tropical Atlantic $\left(-4\right.$ to $-5 \times 10^{-6} \mathrm{~kg} \mathrm{~m}^{-2}{ }^{-1}$ ) where cold upwelling waters are warmed by the solar radiation, and to the southeast of Newfoundland. In general, Fig. 3a is in agreement with the major features of the distribution of the density fluxes diagnosed from the ERA15 and Levitus (1982) surface temperature and salinity by Garnier et al. (2000).

Fig. 3b shows ATL6-ATL1 differences in the original density fluxes. For this diagnostic, high resolution (1/6-degree) results were averaged to 1-degree gridboxes and then the differences were derived. As already mentioned, these differences result only from the deviations between the time mean surface temperature and salinity. They are small and range from $-0.4 \times 10^{-6} \mathrm{~kg} \mathrm{~m}^{-2} \mathrm{~s}^{-1}$ off Newfoundland to $0.2-0.4 \times 10^{-6}$ $\mathrm{kg} \mathrm{m}^{-2} \mathrm{~s}^{-1}$ along the Gulf Stream path, ATL6 diagnosing more intense fluxes than ATL1. In the area of deep

a

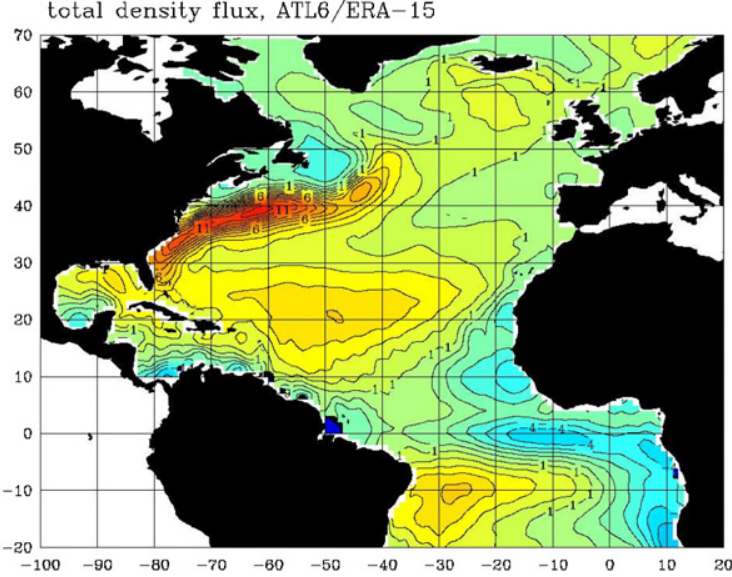

C

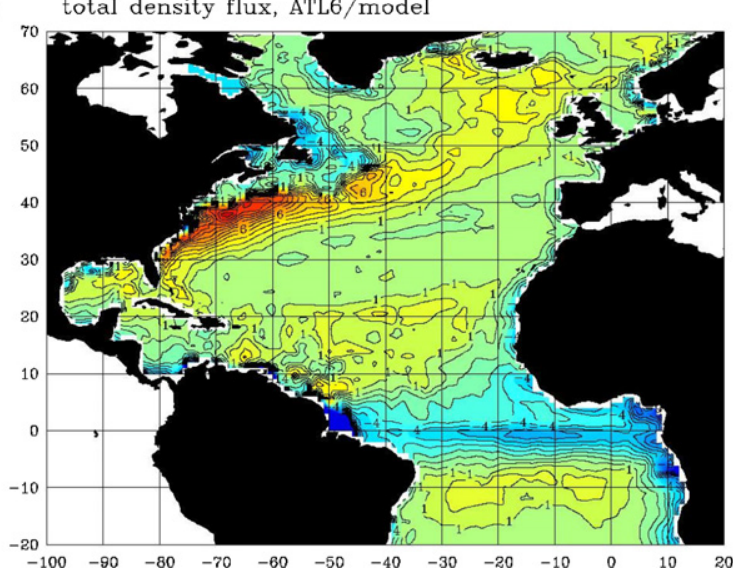

b

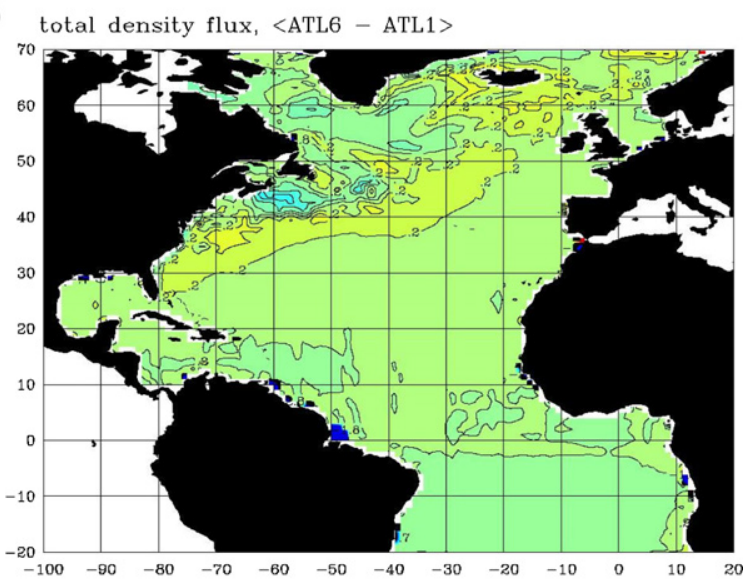

d

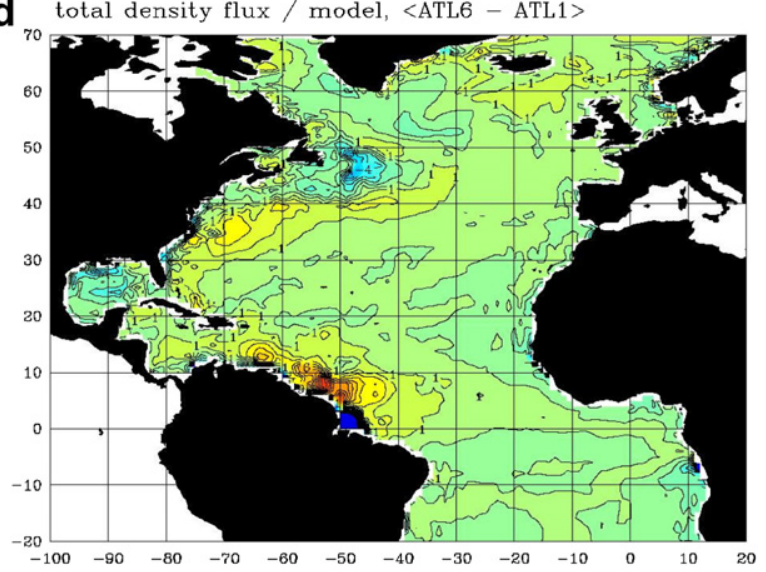

Fig. 3. Distribution of the mean (1982-1993 average) total (thermal + haline) density flux $\left(10^{6} \mathrm{~kg} \mathrm{~m}^{-2} \mathrm{~s}^{-1}\right)$. (a) ATL6 original density flux (i.e. derived from the ATL6 surface temperature and salinity and fluxes from ERA-15 without the feedback term), and (b) difference between ATL6 and ATL1 original density fluxes. (c) Actual density flux diagnosed by ATL6 run (including the feedback term), and (d) difference between ATL6 and ATL1 actual density fluxes. 
convection in the Labrador and Irminger Seas, the ATL6 original density fluxes are smaller than those of the ATL1 by $0.1-0.5 \times 10^{-6} \mathrm{~kg} \mathrm{~m}^{-2} \mathrm{~s}^{-1}$.

The actual density flux diagnosed by the ATL6 run (including the feedback term, Fig. 3c) results from the joint effect of the original density flux (shown in Fig. 3a) and a correction induced by the feedback term in the forcing (not shown). We have to note that although it can be estimated as the algebraic sum of these two terms, the response is nonlinear, since the change of the flux also implies the change of the surface outcrop conditions. Compared to the original density flux, the actual density flux shows significantly greater negative values (generation of lighter waters) in the western equatorial area and on the Greenland and Labrador side of the Labrador Sea (no change is noticed in the central Labrador Sea). It shows smaller positive values in the North Atlantic subtropics (between $10^{\circ} \mathrm{N}$ and $30^{\circ} \mathrm{N}$ ). In all these regions, the feedback term in the forcing has generated a negative density flux which is as large as the original density flux itself $\left(2-4 \times 10^{-6} \mathrm{~kg} \mathrm{~m}^{-2} \mathrm{~s}^{-1}\right)$ contributes to the production of lighter waters. In the eastern subpolar gyre, the actual density flux shows greater positive values, indicating that the generation of dense water by the original ERA15 fluxes is reinforced (by $40-60 \%$ ) by the feedback term.

Fig. 3d shows the differences in the actual density fluxes between ATL6 and ATL1. Higher resolution results in stronger density fluxes in the Gulf Stream area, where the differences are $1-4 \times 10^{-6} \mathrm{~kg} \mathrm{~m}^{-2} \mathrm{~s}^{-1}$, i.e. $10-40 \%$ of the magnitude of flux, and the North Brazil Current (NBC) retroflection area, two regions already identified as those where the discrepancies in winter surface density are the greatest (Fig. 2), and where mesoscale eddies (Gulf Stream rings and NBC eddies) are particularly active in ATL6 (e.g. Penduff et al., 2004). This is an indication of the impact of synoptic eddies on the density fluxes. Synoptic eddies make the relaxation (1) and (2) more complicated in comparison to the non-eddy-resolving experiment and impose additional density flux (i.e. enhanced formation of dense water). In contrast, in the Labrador and Irminger seas, the total density flux diagnosed by ATL1 is slightly higher than in ATL6. The potential reason for that is a considerable underestimation of the EKE in the Labrador Sea area in ATL6, which does not provide an effective resolution of eddies north of $50^{\circ} \mathrm{N}$. Consequently, the effects of eddy processes on the summertime restratification of the central Labrador Sea (Straneo, 2006; Chanut et al., submitted for publication) are greatly underestimated in ATL6, whereas sub-grid scale parameterizations in ATL1 may mimic part of the eddy-driven processes.

We have compared the individual contribution of the thermal and haline correction terms to the actual density flux in both ATL1 and ATL6 (no figure shown). In both experiments, the thermal correction is typically larger than the haline correction, contributing locally from $60 \%$ to $99 \%$ to the total correction. The magnitude of the thermal correction in ATL1 is $20-70 \%$ higher than in the ATL6 experiment. A coarse resolution model appears to require higher thermal correction due to slower and mislocated surface boundary currents. Since shifts in surface fronts often produce biases of the same sign in SST and SSS, the haline correction terms usually work to compensate the effect of the thermal correction. This is clear in ATL6, where the two correction terms have opposite signs in regions of large boundary currents associated with fronts (the Grand Banks, north of the Gulf Stream and in the western equatorial area). It is less clear in ATL1 in the western equatorial region, where the haline correction (negative) works in the same direction as the thermal correction. This difference indicates the effect of the highly variable North Brazil current in the eddy-resolving experiment ATL6.

The differences identified between models for the mean climatology (1982-1993 average), become especially pronounced during winter in mid and high latitudes. Fig. 4 shows the actual density flux diagnosed by the ATL6 experiment and the difference in the value of this flux between the ATL6 and ATL1 for January. Strong positive density fluxes observed over the Gulf Stream $\left(30-40 \times 10^{-6} \mathrm{~kg} \mathrm{~m}^{-2} \mathrm{~s}^{-1}\right)$ provide the winter transformation of surface waters making them denser at all latitudes north of $5^{\circ} \mathrm{N}$. The largest winter differences in the density flux between ATL6 and ATL1 are observed over the Gulf Stream and the North Brazil current, and range from 6 to $8 \times 10^{6} \mathrm{~kg} \mathrm{~m}^{-2} \mathrm{~s}^{-1}$. ATL6 shows surface density flux higher than those of ATL1 almost everywhere except in the Amazon runoff area, the Gulf of Mexico, the Grand Banks and in the interior Labrador and Irminger seas. Greater density fluxes in ATL1 in these regions of the subpolar gyre are likely to result from a horizontal mixing process of newly convected waters with the surrounding waters which is more consistent in the coarse resolution ATL1 model (parameterized by a strong isopycnal diffusivity) than in the ATL6 model (which is locally non-eddy permitting, with no parameterization of unresolved eddies). 

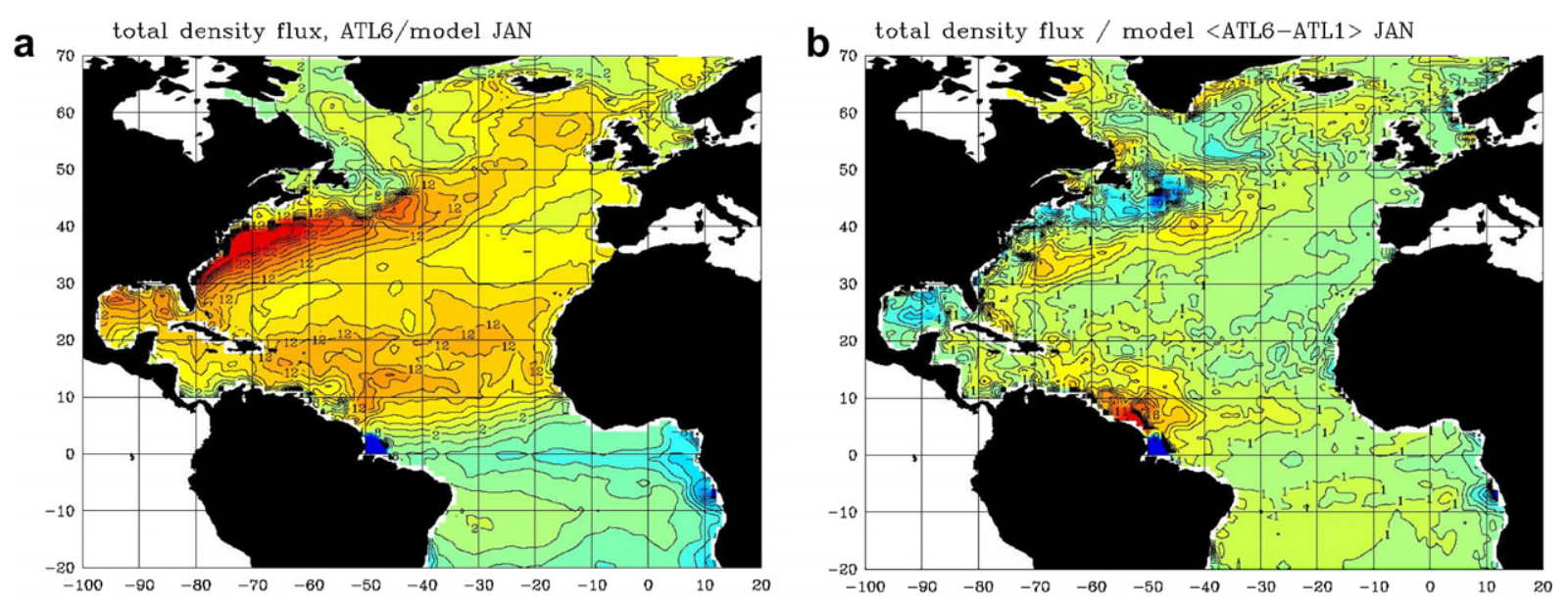

Fig. 4. Winter (January) mean (1982-1993 average) actual density flux $\left(10^{6} \mathrm{~kg} \mathrm{~m}^{-2} \mathrm{~s}^{-1}\right)$ diagnosed by ATL6 (a) and the difference between the actual winter density fluxes of ATL6 and ATL1 (b).

\subsection{Surface transformation rates in ATL1 and ATL6}

Surface density forcing initiates the transformation of the surface water masses, the rate of which can be estimated by the integration of the density flux (3) in space and time for given density (or $T, S$ ) classes (e.g. Walin, 1982; Speer and Tziperman, 1992; Nurser et al., 1999; Ladd and Thompson, 2001):

$$
F(\rho)=\frac{1}{T} \int_{T} \mathrm{~d} t \iint_{\Sigma} f \cdot \delta\left(\rho-\rho^{\prime}\right) \mathrm{d} \Sigma
$$

where the $\delta$ function samples the density flux $f$ over the area where waters of density $\rho$ are outcropping within the integration area $\Sigma$. Being scaled with the unit density (Nurser et al., 1999; Speer et al., 1995), the transformation rate shows the volume of water of density $\rho$ which is transformed during the period of integration (generally one or several annual periods), into higher densities $(F(\rho)>0)$ or lower densities $(F(\rho)<0)$ by the action of the atmospheric forcing. Since $F(\rho)$ results from a spatial integration, it does not explicitly contain the information about the latitudes at which water mass transformation happens. This is why its interpretation requires reference to the winter outcropping lines of density surfaces (shown in Fig. 2) allowing to locate the areas corresponding to a given density class.

Fig. 5a compares the distribution by density classes of the mean transformation rate $F(\rho)$ diagnosed by ATL1 and ATL6 with the actual model fluxes (ERA15 with feedback term included). The density $\sigma_{0}=24.4$ appears as the density around which the transformation rate changes sign. This density delimits the equatorial and tropical waters (which are made lighter by the surface fluxes) from the subtropical and subpolar waters (which are made denser by the action of the atmospheric forcing). In winter the delimiting line (Fig. 2) stretches zonally across the Tropical Atlantic from Senegal $\left(12^{\circ} \mathrm{N}\right)$ to Cuba $\left(20^{\circ} \mathrm{N}\right)$. Note that if we compare ATL1 and ATL6 transformation rates with those diagnosed by the ERA15 fluxes alone (without including the feedback term), we find that ATL6 is always closer to the original ERA rates (Fig. 5a) in regions where ATL6 resolves eddies. However, at densities larger than 27.5 ATL1 rates are slightly closer to the original ERA15 rates compared to ATL6. This indicates a greater consistency between ATL6 solution with the original ERA15 fluxes where the high resolution model resolves eddies, suggesting a lesser bias in the surface circulation in ATL6 than in ATL1, and inversely implies that the eddy parameterization used in ATL1 is working better than the bi-harmonic diffusivity applied in ATL6 when eddies are not resolved. In Section 4 (summary and discussion) we will discuss the possible effects of increasing lateral mixing in eddy-permitting resolution experiments.

In the equatorial area $\left(\sigma_{0}<24.4\right)$ the differences between ATL1 and ATL6 are the greatest. The maximum rate of transformation of light equatorial waters is located around $\sigma_{0}=23.2$, and is significantly greater in the coarse resolution ATL1 run (30 Sv) than in the eddy-resolving run ATL6 (23 Sv). At this density, the feedback 

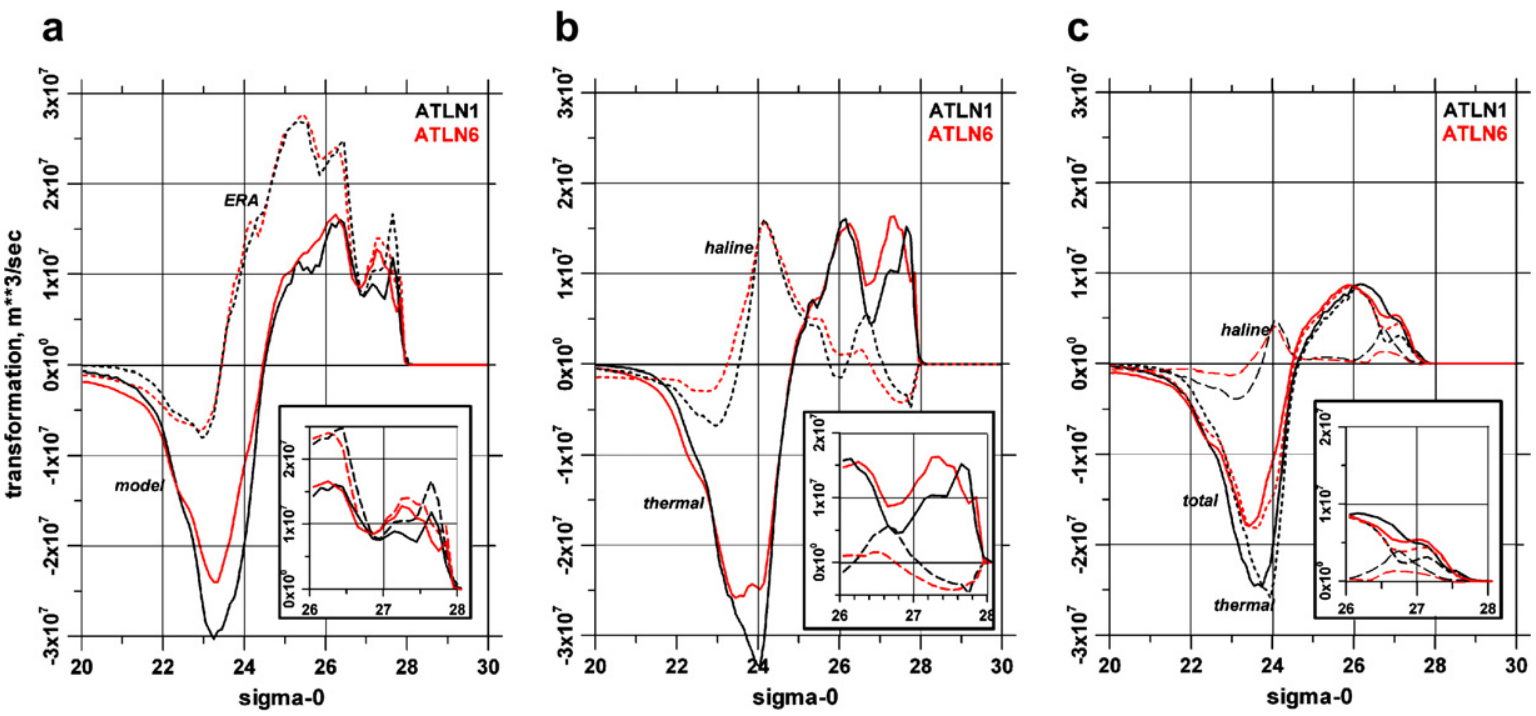

Fig. 5. (a) The total surface water mass transformation derived from the original ERA15 surface density flux (dotted lines) and diagnosed by model runs (solid lines). (b) Thermal (solid lines) and haline (dotted lines) surface water mass transformation diagnosed by model runs. (c) Total (solid lines), thermal (dotted lines) and haline (dashed lines) surface water mass transformation diagnosed by model runs over the areas where the EKE is higher than $100 \mathrm{~cm}^{2} / \mathrm{s}^{2}$ in ATL6. Black lines correspond to ATL1 and red lines to ATL6. Zoom-windows for each panel show enlarged view for the density range $26<\sigma_{0}<28$.

term of the forcing (Eq. (1)) is mainly responsible for this. The SST produced by both models is too cold in this region, so the flux correction is adding heat into the ocean producing more light waters.

In the density range of subtropical waters $\left(24.4<\sigma_{0}<26.5\right)$, transformation rates are rather similar between the two models. The only noticeable difference is a slightly greater transformation rate at $\sigma_{0}=$ 25.5 in ATL6 ( $2 \mathrm{~Sv}$ above ATL1 which rate is $10 \mathrm{~Sv}$ ). Although large differences in actual density flux were seen between models in the regions covered by this density range (Fig. 3c and d), it seems that the averaging by density classes produces similar transformation rates. Both model experiments identified clearly a peak at $26.0<\sigma_{0}<26.5$ corresponding to the transformation of subtropical mode waters (STMW). At these densities the transformation rates diagnosed by the ERA15 data alone are about $8 \mathrm{~Sv}$ higher compared to those diagnosed by the actual model surface flux in both ATL1 and ATL6 experiments (Fig. 5a). As the result, the formation rate of STMW (proportional to $\partial F / \partial \sigma$ ) implied by ERA15 forcing alone is about twice as large in comparison to the actual forcing in both simulations (16 Sv vs 7-8 Sv), being consistent with Marsh (2000) and Haines and Old (2005), but smaller than reported by Marshall et al. (1999). Quite large correction terms in both ATL1 and ATL6 experiments can be largely explained by considerable overestimation of surface latent heat flux in ERA15 in the region of STMW formation. Evaluation of different flux products (WGASF Group, 2000) reported about $20 \mathrm{~W} / \mathrm{m}^{2}$ higher latent heat fluxes in ERA15 compared to COADS-based fluxes (da Silva et al., 1994), explaining more than $80 \%$ of differences between the net surface heat fluxes in ERA15 and COADS fluxes constrained by hydrographic data. The northward shift of the Gulf Stream is also a contributing factor.

At subpolar latitudes (densities higher than 27), the two experiments exhibit important differences in the surface water mass transformation. It is then useful to recall that the ATL6 model is not resolving eddies at latitudes north of $50^{\circ} \mathrm{N}$, corresponding to density classes higher than 27 . The coarse resolution ATL1 model shows a small peak ( $8 \mathrm{~Sv}$ ) at $\sigma_{0}=27.1$, corresponding to the transformation of North Atlantic Subpolar mode waters (SPMW), and a well marked peak $(12 \mathrm{~Sv})$ at $\sigma_{0}=27.7$ corresponding to the transformation of the LSW. In ATL6, the peak corresponding to the transformation of SPMW in the eastern subpolar gyre is greater $(12.5 \mathrm{~Sv})$ and is slightly shifted toward greater densities $\left(\sigma_{0}=27.3-27.5\right)$. In the Labrador Sea, the ATL6 experiment shows a small peak $(\sim 6 \mathrm{~Sv})$ at very high densities $27.75-27.8$ corresponding to the LSW transformation, consistent with the weak density flux in the central Labrador Sea in this experiment (Fig. 3c). 
Fig. 5b separates the contribution of the thermal and haline forcing to the surface water mass transformation in the two models. In the equatorial area $\left(23<\sigma_{0}<24\right)$ where lightening of the surface waters in ATL1 is considerably stronger than in ATL6 (see Fig. 5a), both thermal and haline transformation contribute to this disagreement. Thermal transformation of STMW $\left(\sigma_{0} \sim 26\right)$ is very comparable in the two runs, with the haline contribution being smaller in this density range, with however an significant difference between the two runs: the haline contribution reinforces the thermal contribution in ATL6, whereas it opposes it in ATL1. At densities $26.5<\sigma_{0}<27.1$ (corresponding to the relative minimum between the STMW and SPMW peaks) the total transformation rates (Fig. 5a) are relatively similar in ATL1 and ATL6. However, in ATL1 the thermal and haline contributions have the same strength, whereas in ATL6 the total transformation is largely dominated by the thermal transformation. Therefore, the interplay between the haline and thermal contributions appears to be significantly different between both experiments in the density range of STMW, due to different quantitative impacts of resolution on each component.

At subpolar latitudes $\left(\sigma_{0}>27\right)$, the difference between ATL1 and ATL6 in the transformation of SPWM and LSW is almost exclusively due to the thermal transformation. Given the importance of synoptic eddies in the high resolution ATL6 experiment, we estimated surface water mass transformation over the areas where the eddy kinetic energy (EKE) is higher than $100 \mathrm{~cm}^{2} \mathrm{~s}^{-2}$ (Fig. 5c). This area is shown in Fig. 2c and covers the equatorial currents, the Gulf Stream and NAC. In the equatorial band $\left(10^{\circ} \mathrm{S}-10^{\circ} \mathrm{N}, \sigma_{0}<23.8\right)$, the ATL6 run simulates a lightening of the surface waters by about weaker $30 \%$ than in ATL1. In both runs the thermal contribution largely dominates over the haline term. Along the Gulf Stream path $\left(25<\sigma_{0}<26\right)$ transformation rates are near-identical in ATL1 and ATL6 and are fully dominated by the thermal contribution. At densities ranging from 26.0 to 27.0, corresponding to the NAC waters, ATL1 demonstrates a somewhat stronger transformation than ATL6 does mostly due to a greater haline term. Generally, Fig. 5c does not imply that eddies are critical for surface transformation, but implies a different balance between thermal and haline contribution.

The mean seasonal cycle of the surface water mass transformation in the two experiments is compared in Fig. 6. Both models simulate a well marked seasonal cycle, characterized by an alternation of periods of negative and positive surface transformation. The period of negative transformation rate (formation of light waters in summer) progressively shortens as the density range considered increases. The lightest equatorial waters $\left(\sigma_{0}<23\right)$ do not experience a phase of densification during the year, whereas this period of increase of the surface stratification lasts about 5 months (from April to August) for subtropical or subpolar waters $\left(\sigma_{0}>26.5\right)$. Differences between the two models are mainly visible in the amplitude of the annual cycle which is significantly greater in ATL1. During the period of increasing stratification, ATL1 shows systematically stronger negative transformation rates. At densities $22<\sigma_{0}<26$, this difference amounts up to $30 \%$ of the mean values. During the winter period when the atmospheric forcing makes the surface waters denser, ATL6 demonstrates stronger positive transformation at densities $26.8<\sigma_{0}<27.5$, but considerably weaker transformation for the waters with densities $27.5<\sigma_{0}<27.8$ corresponding to the water generated by the convection in the Labrador and Irminger seas. This winter signature results in the pattern clearly seen in the mean annual curves (Fig. 5a).

\subsection{Transformation rates in the T,S-plane for ATL1 and ATL6 experiments}

We now consider the transformation rate $F(\rho)$ diagnosed by ATL1 and ATL6 experiments in the $T, S$-plane. This allows for identification of the density fluxes with the cores of water masses formed at the surface. Figs. $7 \mathrm{a}$ and $\mathrm{b}$ show the annual mean of the surface water mass transformation in the $T, S$-plane for the experiments ATL6 and ATL1. As in Figs. 5 and 6 negative $F(\rho)$ values in Fig. 7 correspond to a negative density flux in the ocean (forming lighter waters) and positive values reflect ocean densification. The formation rate, given by the derivative of transformation rate with respect to density, corresponds to gradients across the isopycnals in Fig. 7. The coarse resolution experiment shows stronger negative transformation rates of equatorial and tropical waters $\left(\sigma_{0}<24.5\right)$. For the $T, S$-classes corresponding to the STMW $\left(T=18-19^{\circ} \mathrm{C}\right.$ and $S=$ 36.3-36.5, $26<\sigma_{0}<26.5$ ), somewhat higher surface water mass transformation rates are observed in experiment ATL6. Note that STMW in both ATL1 and ATL6 experiments is somewhat fresher than in nature. Similarly, for the SPMW $\left(26.5<\sigma_{0}<27.5\right)$ the peak of transformation for the $11^{\circ} \mathrm{C}$ waters $\left(T=11^{\circ} \mathrm{C}\right.$ and 

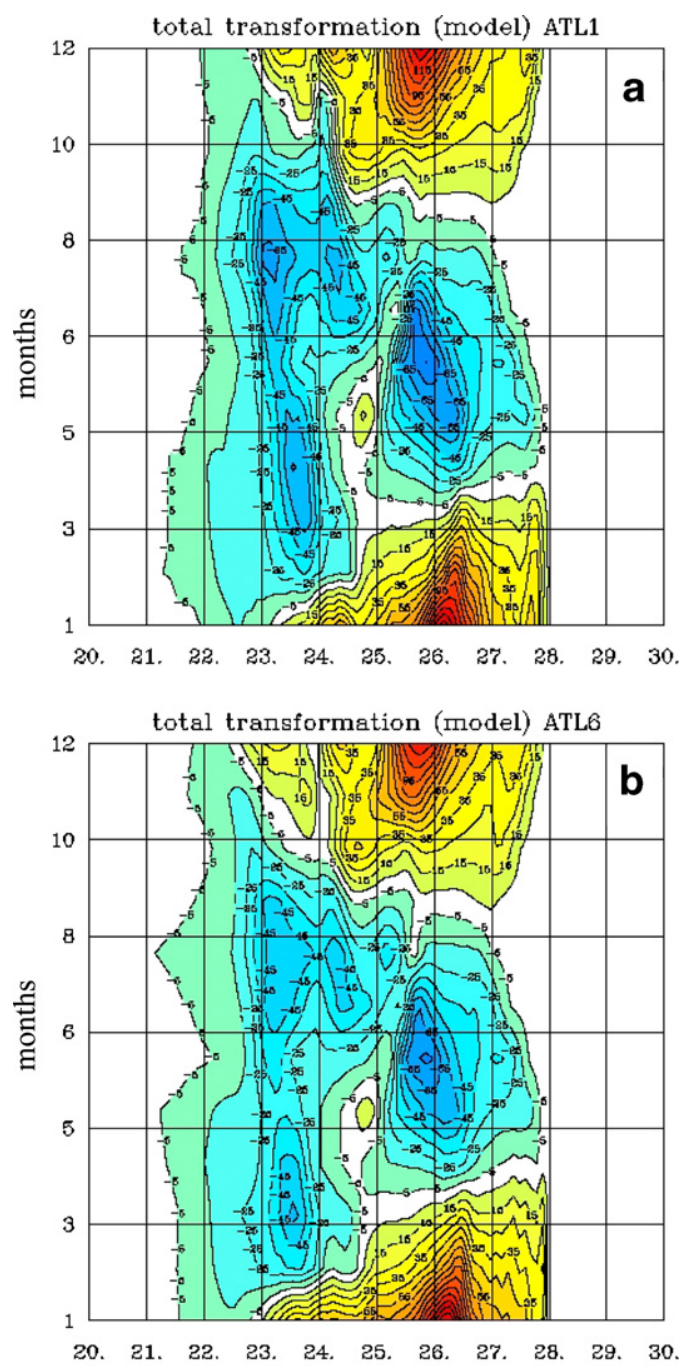

Sigma-0

Fig. 6. Seasonal cycle of the total surface water mass transformation, diagnosed by the model in ATL1 (a) and ATL6 (b) runs. Units are in Sv.

$S=35.5$ ) is better marked in ATL6. Note that in ATL6 most SPMW are formed at densities greater than 27, thus in the areas where eddies are not correctly resolved in the model. For the waters denser than $\sigma_{0}=27.5$ corresponding to the LSW, the maximum transformation rate occurs at a colder temperature in ATL6 (below $3{ }^{\circ} \mathrm{C}, S=35$ ) than in ATL1 (above $3{ }^{\circ} \mathrm{C}, S=35$ ). Thus, the LSW is produced in ATL6 experiment at high densities which are not present in ATL1.

The peculiarities identified for the annual mean become even more pronounced in winter (Fig. 7c). All waters colder than $26{ }^{\circ} \mathrm{C}$ are getting denser under the action of the atmospheric forcing in the cold season. Winter differences between surface water mass transformation in ATL6 and ATL1 experiments (Fig. 7d) shows that the maxima of water mass transformation for subtropical and subpolar mode waters in the ATL6 experiment occurs at higher densities compared to ATL1. The surface transformation rate of the LSW is generally higher in the ATL1 experiment.

To investigate the possible effect of eddies, we look at the winter transformation rates in $T, S$-coordinates for the area of high EKE (EKE $>100 \mathrm{~cm}^{2} / \mathrm{s}^{2}$, see Fig. 2c) in ATL6 experiment (Fig. 8a). Water masses influenced by the effects of eddies are equatorial and tropical waters $\left(T>26{ }^{\circ} \mathrm{C}\right)$, STMW $\left(26.0<\sigma_{0}<26.5\right)$ and 
SPWM formed in the NAC $\left(10^{\circ} \mathrm{C}<T<14^{\circ} \mathrm{C}\right)$. The difference between surface transformation rates in ATL6 and ATL1 for this area (Fig. 8b) demonstrates much stronger surface transformation in the tropics and Gulf Stream area at the densities from 23.5 to 26.0 in ATL6 run compared to ATL1. In the NAC area and in the subpolar gyre over the areas with EKE $>100 \mathrm{~cm}^{2} / \mathrm{s}^{2}$, Fig. $8 \mathrm{~b}$ brings a message quite similar to that revealed from Fig. 7d, i.e. that ATL6 experiments in the density range of SPMW is providing transformation on greater densities compared to ATL1 run. Although these results cannot directly imply the role of synoptic eddies in surface transformation, diagnostics of the same experiment by Valdivieso Da Costa et al. (2005) demonstrated that synoptic eddies play an important role in overall formation rates in the Gulfstream area.
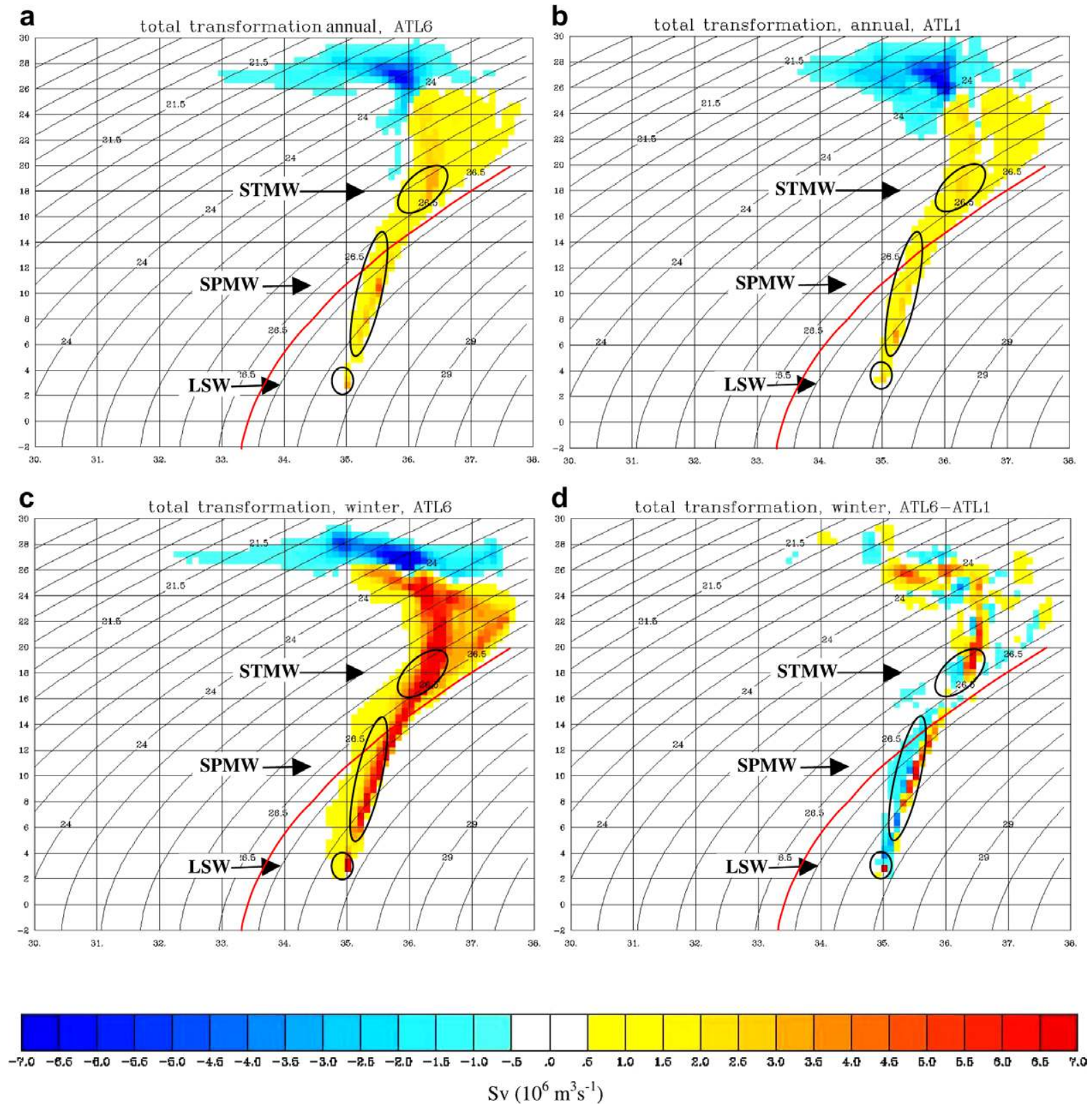

Fig. 7. Mean (1982-1993 average) surface transformation rates (in Sv) in the $T, S$-plane diagnosed by ATL6 (a) and ATL1 (b) runs, winter (JFM) transformation from ATL6 run (c), difference between the winter surface transformations in ATL6 and ATL1 runs (d). The red curve outlines the density $\sigma_{0}=27$, the tentative limit of the eddy resolution in ATL6. 


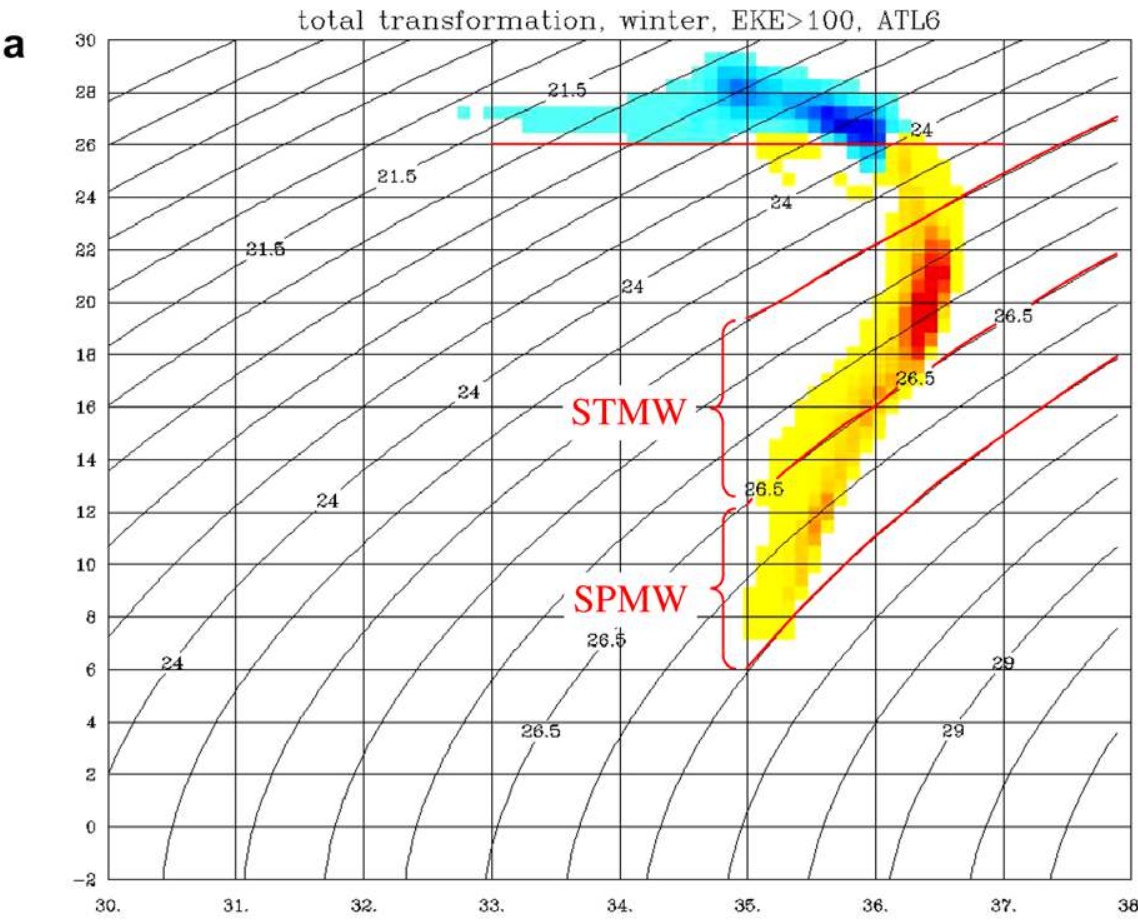

b
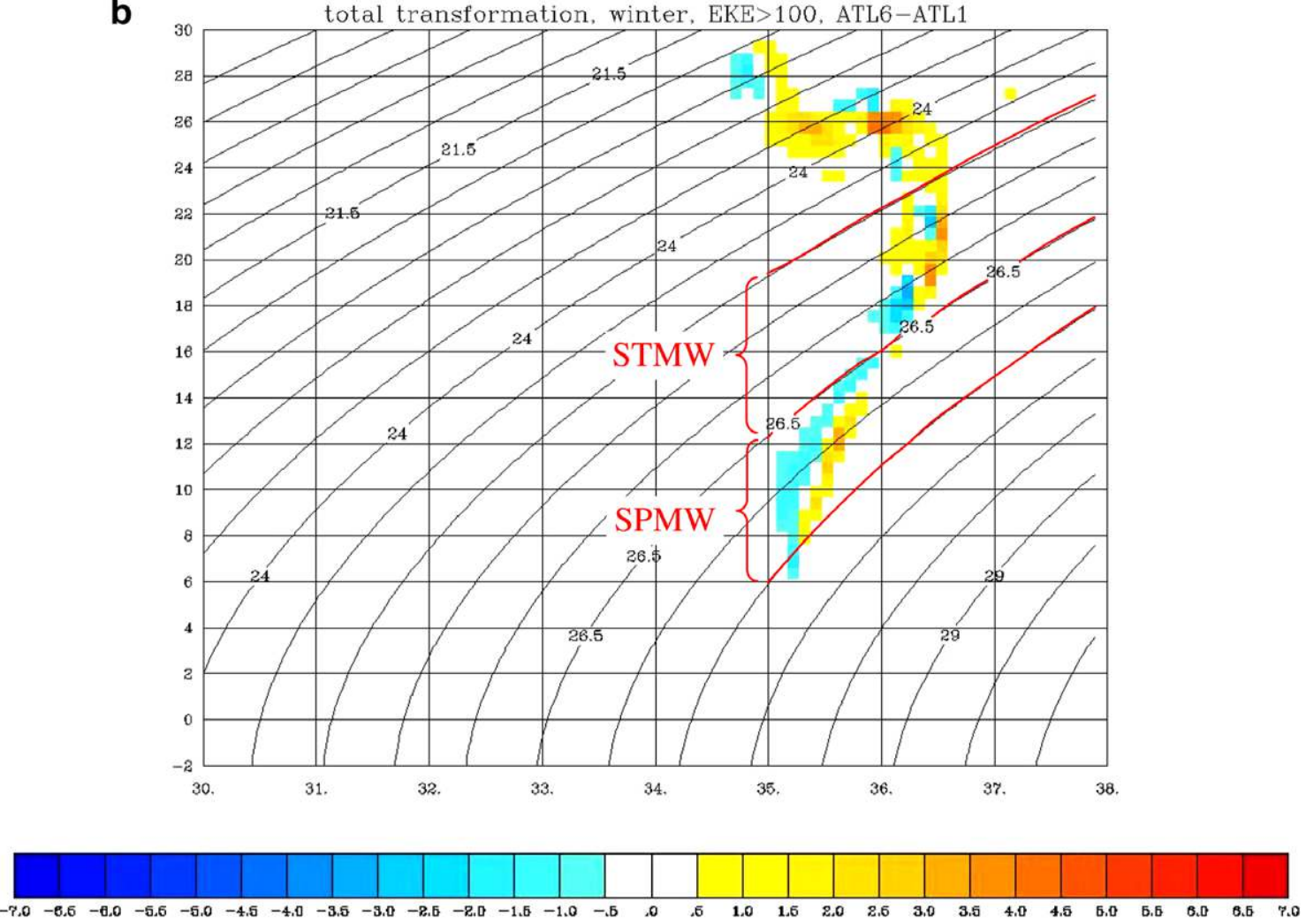

Fig. 8. Winter total surface transformation in $T, S$-plane diagnosed by ATL6 experiment over the area where EKE $>100 \mathrm{~cm}^{2} / \mathrm{s}^{2}$ (a) and the difference between the winter surface transformations in ATL6 and ATL1 runs over the area where EKE $>100 \mathrm{~cm}^{2} / \mathrm{s}^{2}(\mathrm{~b})$. 


\subsection{Overturning driven by surface water mass transformation in ATL1 and ATL6 experiments}

Surface water mass transformation allows for the estimation of a surface forced overturning stream function, first introduced by Marsh (2000) and also used by Gulev et al. (2003) for the diagnostics of the decadal variability in the coarse resolution SPEM model. Following Marsh (2000), we integrated in the longitudinal direction the local water mass transformation $f$ for each density $\sigma$ over the areas where $\sigma_{\text {surf }}>\sigma$ :
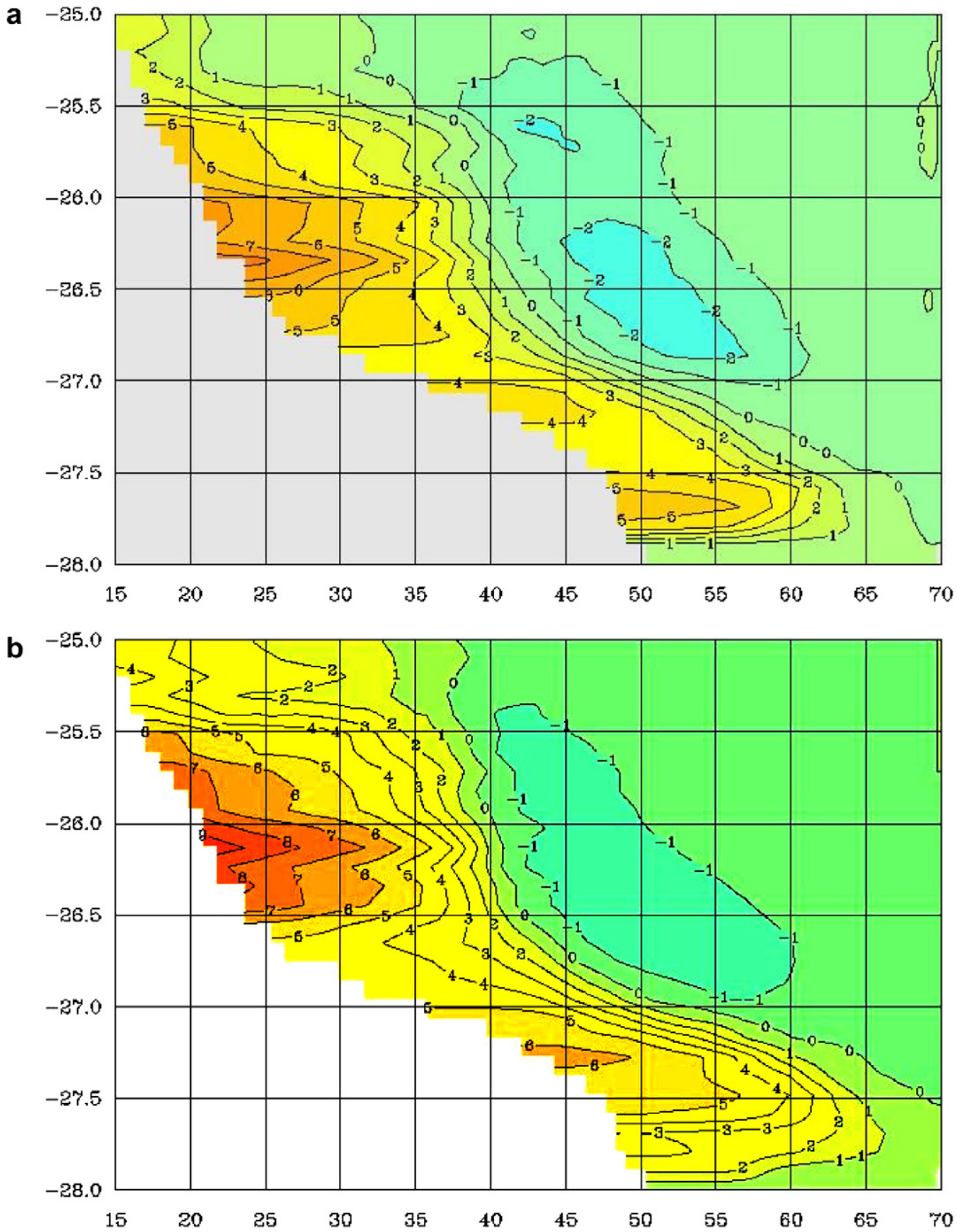

Fig. 9. The mean distribution of the surface forced overturning stream function derived from ATL1 (a) and ATL6 (b) experiments. 


$$
\Phi_{\sigma}\left(\varphi_{\sigma}, \sigma\right)=\int_{\varphi_{\sigma}}^{\varphi_{0}} \mathrm{~d} \varphi \int f(\varphi, \lambda) H(\sigma) \mathrm{d} \lambda, \quad H= \begin{cases}1, & \sigma_{\text {surf }}>\sigma, \\ 0, & \sigma_{\text {surf }} \leqslant \sigma\end{cases}
$$

( $\lambda$ denotes longitude, $\varphi$ denotes latitude). Being scaled with the unit density, $\sigma_{\sigma}$ can be interpreted as the surface forced overturning stream function (Marsh, 2000) and shows the water mass transformation in latitudedensity coordinates. Mean distributions of $\sigma_{\sigma}$ derived from the ATL1 and ATL6 experiments are shown in Fig. 9. Surface forced overturning derived from the ATL1 run (Fig. 9a) shows three maxima of the intensity of overturning corresponding to the major water masses STMW, SPMW and LSW. This picture is qualitatively comparable to the results of a 40-year experiment with the 1-degree resolution SPEM model (Gulev et al., 2003) and to the diagnostic study of Marsh (2000), who used for his computation the air-sea fluxes from the SOC climatology (Josey et al., 1999) and a surface density derived from the $T$ and $S$ climatology of Levitus (1982). In comparison to the SPEM results (Gulev et al., 2003) the surface forced overturning of the LSW is weaker in ATL1 and the surface overturning of STMW is somewhat stronger, showing values of 7-8 Sv comparable with the estimates of Marsh (2000) for these waters. If we consider the ATL6 experiment (Fig. 9b), it shows a considerable modification of the surface forced overturning stream function. We observe in Fig. 9b an intensification of the overturning of the STMW by approximately $2.5 \mathrm{~Sv}$ and considerable increase of the overturning in the SPMW density range (27.0-27.5) in the latitudinal band $40-55^{\circ} \mathrm{N}$, corresponding to the location of NAC. In this area the values of surface forced overturning stream function in ATL6 experiment are 50-70\% stronger than in the ATL1 run. At the same time, at densities and latitudes corresponding to the transformation of the LSW, ATL6 shows pronounced weakening of surface forced overturning in comparison to ATL1. At these densities ATL6 indicates 2-3 Sv at $\sigma_{0}=27.7-27.8$, while ATL1 shows values of about 5-5.5 Sv. Note, however, that for the very dense waters (27.8-27.9) ATL6 again shows somewhat higher values of surface forced overturning stream function than ATL1.

Results of Fig. 9 can be compared with the overturning stream function, plotted in "latitude- $\sigma_{0}$ " coordinates (Fig. 1). For the density range of STMW (upper box in Fig. 1) ATL6 shows stronger by 1-2 Sv overturning compared to ATL1. In the density range 27.0-27.5 corresponding to SPMW (middle box in Fig. 1), overturning stream function is also somewhat stronger in ATL6 than in ATL1. These features are qualitatively comparable with peculiarities seen for surface forced overturning (Fig. 9). At high densities $\left(\sigma_{0}=27.5\right.$, lower box in Fig. 1) ATL6 run shows also stronger overturning (approximately 12-14 Sv) than ATL1 experiment (about 10-12 Sv), whereas the surface forced overturning (Fig. 9) is greater in ATL1. It is not possible without an additional analysis to unambiguously attribute these changes in surface overturning to changes is diapycnal mixing, because of the changes seen in the horizontal circulation are evident between the two experiments. The fact that the intensity of the subpolar gyre circulation is significantly stronger at $1 / 6^{\circ}$ (a gain of $15 \mathrm{~Sv}$, CLIPPER Team, 2001) explains largely the difference in overturning at subpolar latitudes.

\section{Summary and conclusions}

We analysed characteristics of the water mass transformation in the North Atlantic in coarse $\left(1^{\circ}\right.$, ATL1) and high $\left(1 / 6^{\circ}\right.$, ATL6) resolution experiments with the identical configuration of the CLIPPER model and ERA-15 forcing. Surface transformation rates showed noticeable differences in climatological characteristics of surface water mass transformation in the two experiments. The higher resolution experiment ATL6 showed stronger surface transformation in the equatorial and tropical regions, in the Gulf Stream area and the location of the formation of STMW, and in the lightest SPMW $\left(11^{\circ} \mathrm{C}\right.$ waters $)$ associated with high levels of the eddy kinetic energy. At the same time, ATL1 which does not allow eddies to grow, shows a better representation of the transformation rates corresponding to the densest SPMW and LSW. Analysis of the surface transformation rates in a $T, S$-plane and surface forced overturning, has shown that SPMW are saltier and that LSW are colder in ATL6. Our analysis has also shown that the peak in surface transformation at LSW densities appears to be better represented in ATL1.

The main differences between the two experiments are the resolution and associated formulation of lateral mixing. High resolution in the experiment ATL6 provides adequate representation of mesoscale eddies at latitudes south of $50^{\circ} \mathrm{N}$. In this area, $1 / 6^{\circ}$ resolution results in intensive turbulence of the Gulf Stream and NAC, and, thus, does affect the characteristics of the water mass transformation due to non-linearity of Eq. (3)-(5). 
At $1^{\circ}$ resolution, local effects of mesoscale eddies are generally represented by isopycnal diffusion as in ATL1, at least in the low latitude bands where parameterizations based on a bolus velocity as proposed by Gent and McWillams (1990) (GM90) have demonstrated a limited positive impact (McWilliams and Danabasoglu, 2002), because they are not able to account for coherent structures such as NBC rings.

Since it is in this band of latitudes that we noticed the largest discrepancies in water mass transformation and overturning between ATL1 and ATL6, one may wonder if actual parameterizations of lateral mixing used in climate models are adequate for tropical regions. This advocates for resolving eddies, especially in the NBC region where the effects of eddies are largely non-local since NBC rings are able to drift as coherent structures over long distances (Barnier et al., 2001; Fratantoni and Richardson, 2006).

$1 / 15^{\circ}$
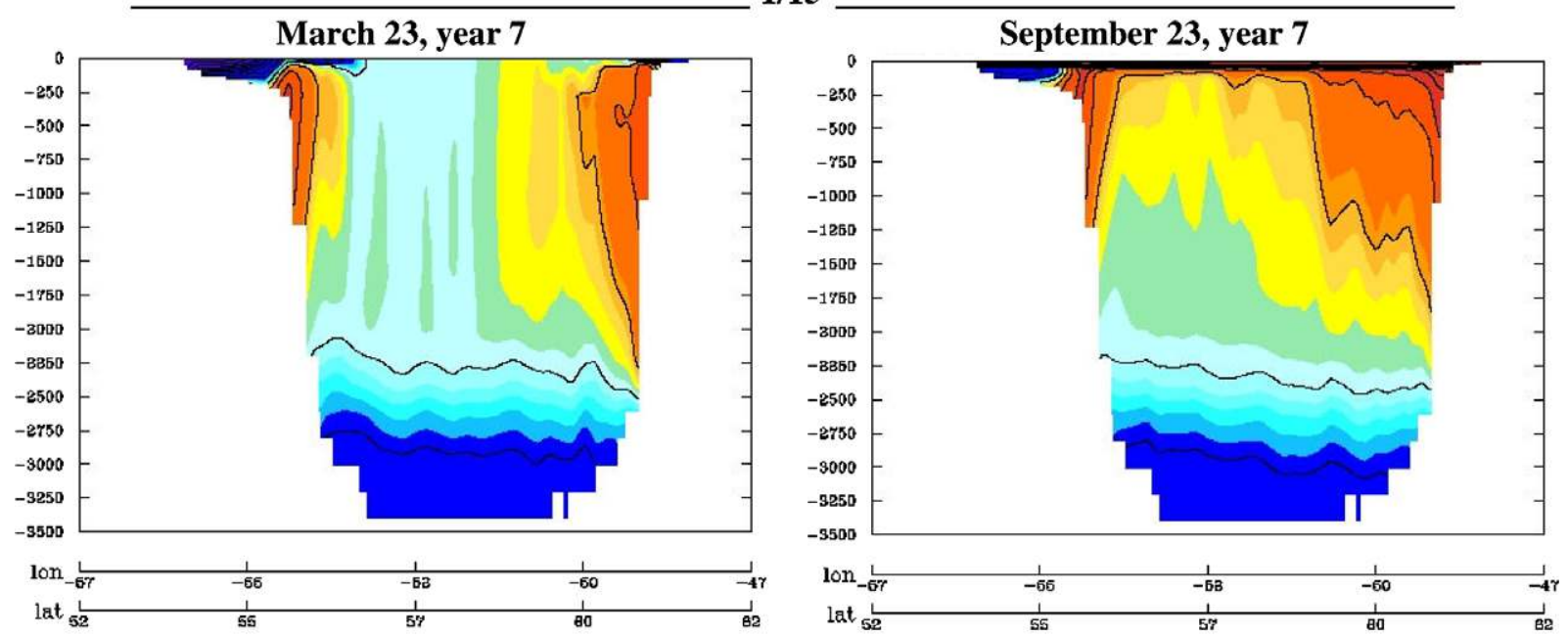

$1 / 6^{\circ}$
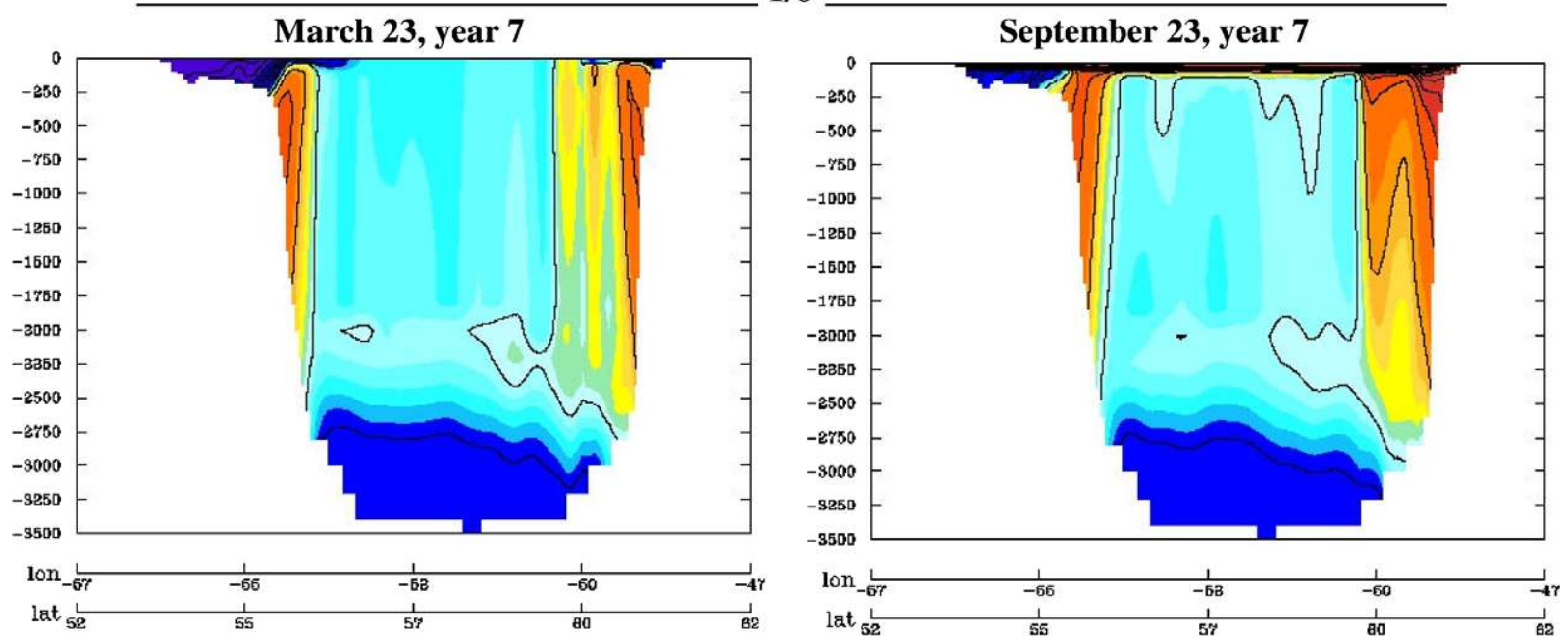

Fig. 10. Snapshots of the vertical distribution of potential temperature across the Labrador Sea at the location of the WOCE AR7W section in March (left plots) and in the following September (right plots) in the eddy-resolving $1 / 15^{\circ}$ CLIPPER model (upper plots) and the eddy-permitting ATL6 model (lower plots) after 7 years of a spin-up experiment driven with ERA15 seasonal climatology (1979-1993 average). Reconstruction of the stratification in summer by air-sea fluxes covers the whole basin but does not extend deeper than $50 \mathrm{~m}$. In the $1 / 15^{\circ}$ case, the interior Labrador Sea is re-stratifies down to $1500 \mathrm{~m}$ in summer, heat being fluxed by eddies from the (warmer) boundary current (oscillations in the isotherms are signatures of eddies). In the $1 / 6^{\circ}$ case, eddies are fewer and weaker in the Labrador Sea because of insufficient resolution. The sub-surface stratification of the interior Labrador Sea is not reconstructed at the end of Summer, the horizontal (bi-harmonic) parameterization used for heat diffusion is clearly not able to flux heat far enough from the boundary current. 
Nevertheless, the resolution of the ATL6 run was not enough to resolve the synoptic processes in the subpolar latitudes. This is seen on the maps of eddy kinetic energy analysed by Penduff et al. (2004). Analysis of the transformation characteristics shows that intense transformation in the ATL6 experiment occurs over the larger domain associated with the subpolar gyre in general, rather than localized in the Labrador Sea and Irminger Sea as in the ATL1 experiment. The differences between the water mass transformation characteristics in the subpolar gyre result mainly from the formulation of mixing in the ATL6 experiment. The ATL6 model is not eddy-resolving in the Labrador Sea. For instance, Chanut et al. (submitted for publication) showed that a resolution of $1 / 15^{\circ}$ is required to have realistic eddy fluxes (see Fig. 10). Therefore, resolved eddies at $1 / 6^{\circ}$ are not sufficient to provide the flux of heat from the (relatively warm) rim current into the central Labrador Sea during summer and fail to rebuild the stratification before the next winter. The other process which could restratify the Labrador Sea after winter convection is the model lateral diffusivity. But at $1 / 6^{\circ}$ resolution, the rim current is rather thin, and the small bi-harmonic diffusivity used in the model is not able to diffuse heat to the interior of the Labrador Sea. Consequently, there is little exchange of heat between the rim current and the interior of the Labrador Sea in ATL6, as shown in Fig. 10. Convection reaches down to the bottom every winter, the Labrador Sea is weakly stratified and the LSW becomes colder and denser (than in ATL1, and than in the $1 / 15^{\circ}$ model. The ATL1 solution is indeed closer to the $1 / 15^{\circ}$ one). For this reason, the peak in transformation corresponding to the LSW occurs at higher densities in ATL6. In ATL1, the rim current is significantly broader (due to coarse resolution) and the higher value of isopycnal diffusivity is efficiently fluxing heat to the interior, contributing to the re-stratification of the Labrador Sea during the warm season. Thus, LSW starts to become warmer and lighter than in ATL6, and the peak corresponding to the transformation of LSW occurs in a density range more comparable to observations.

$1 / 15^{\circ}$

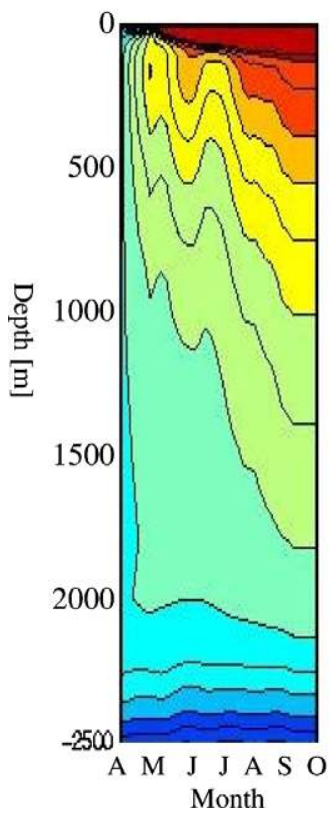

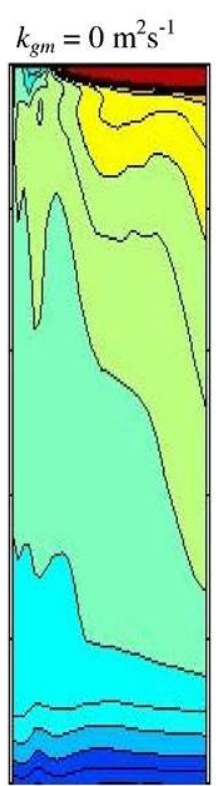

A M J J A S O Month

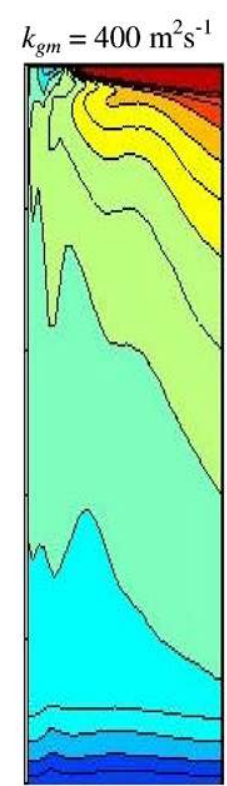

A M J J A S O Month $1 / 3^{\circ}$
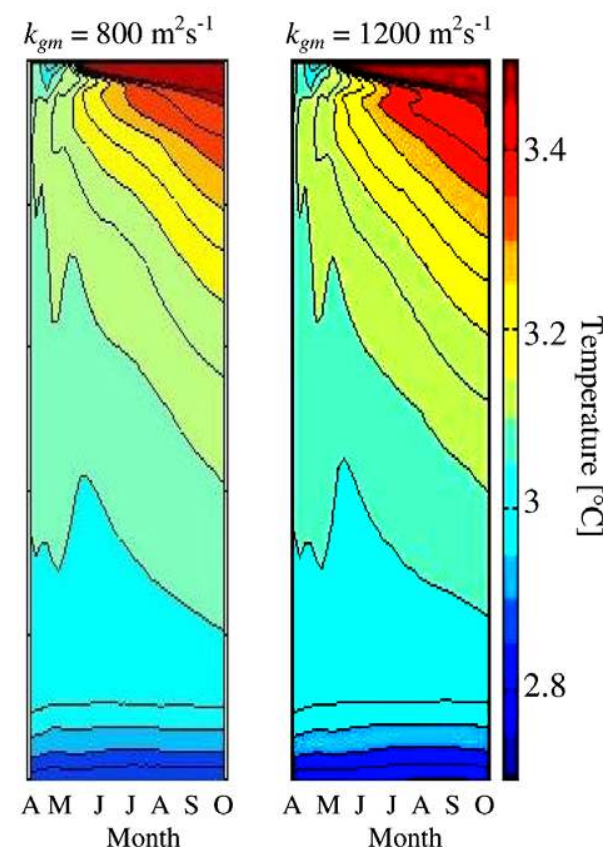

Fig. 11. Time evolution of the potential temperature profile at station BRAVO $\left(56^{\circ} 30^{\prime} \mathrm{N}, 51^{\circ} 00^{\prime} \mathrm{W}\right)$ between April and October (the re-stratification period) for the different experiments (see text). Left plot: Experiment with the $1 / 15^{\circ}$ grid in the Labrador Sea. This is the reference solution that we attempt to reproduce with the other experiments with the $1 / 3^{\circ}$ model and the GM90 parameterization. At the end of winter the temperature is homogenized down to $2000 \mathrm{~m}$, after a convection event of several months. As spring goes by, the water column warms up, but the warming is rather uniform between $100 \mathrm{~m}$ and $800 \mathrm{~m}$, indicating that heat does not come from the surface but from the side, brought in by the eddies. Right plots: the four experiments with the $1 / 3^{\circ}$ model and different values of the eddy viscosity $k_{\mathrm{gm}}$. The value of $800 \mathrm{~m}^{2} \mathrm{~s}^{-1}$ is that which reproduces best the plot on the right. The value $k_{\mathrm{gm}}=0$ corresponds to the standard bi-harmonic diffusivity used in the CLIPPER $\left(1 / 3^{\circ}\right.$ and $\left.1 / 6^{\circ}\right)$ models. It is the one which shows the weakest re-stratification. 
In this respect a reasonable question is whether the increased lateral diffusion in the high resolution experiment can provide realistic re-stratification in the Labrador Sea. We have investigated this question using the eddy-permitting, 1/3 ${ }^{\circ}$ CLIPPER North Atlantic configuration, very similar to ATL6, except for a slightly coarser resolution. In this configuration, resolution could be refined from $1 / 3^{\circ}$ to an eddy-resolving resolution of $1 / 15^{\circ}$ in the Labrador Sea. This configuration was used by Chanut et al. (submitted for publication) to study the role of eddies in the convection/re-stratification cycle in the Labrador Sea. Using several 10-year long experiments with the fine $1 / 15^{\circ}$ grid they showed that a significant growth of the mesoscale eddy activity in the Labrador Sea after convection events was adequately preconditioning the stratification of the interior Labrador Sea (Fig. 10), and was essential to produce a winter mixed layer depth in a good agreement with observations. The eddy-permitting $1 / 3^{\circ}$ (i.e. not refined) model solution, like the $1 / 6^{\circ}$, is showing an unrealistically weak stratification in summer due to inadequate preconditioning (the case with $k_{\mathrm{gm}}=0$ in Fig. 11), and much too deep winter convection. The standard bi-harmonic diffusivity used in the eddy-permitting CLIPPER configurations is thus clearly not adequate to represent the eddy-driven buoyancy flux of the interior Labrador Sea. In order to further study the potential of GM90 parameterization in reproducing the eddy preconditioning effect shown at $1 / 15^{\circ}$ in coarser resolution models, the $1 / 3^{\circ}$ configuration with GM90 has been run for the period April-October using for initial conditions the $1 / 15^{\circ}$ solution at the end of March. Results for four different values of the $k_{\mathrm{gm}}$ coefficient are summarized in Fig. 11. They show that the experiment with the coefficient $k_{\mathrm{gm}}=800 \mathrm{~m}^{2} \mathrm{~s}^{-1}$ provides the best agreement with the direct high resolution computation, and demonstrate that at least in this region, the use of a GM90 parameterization brings a real improvement to the eddy-permitting resolution model. At the same time, as we mentioned above, the use of the GM90 parameterization with the optimal coefficient in the $1 / 3^{\circ}$ degraded considerably the model solution at lower latitudes, resulting for instance in an excessive flattening of isopycnals, and a strong reduction of EKE levels at moderate or low latitudes in regions where the $1 / 3^{\circ}$ resolution should nevertheless allow eddies to be resolved. In this respect the use of spatially varying GM90 coefficient would be more appropriate in the future. We have to also mention the temperature inversions in the upper $500 \mathrm{~m}$ layer in all experiments with $1 / 3^{\circ}$ model which do not appear in $1 / 15^{\circ}$ simulation, being likely salinity compensated in that configuration.

Future development of this study can involve both investigation of the experiments at different resolutions and simulations performed with different models, using different representations of mixing procedures. Of special interest would be the analysis of the experiments with regional grid refining, as in the case of Chanut et al. (submitted for publication). Further diagnostics of water mass transformation should also include representation of mixing processes which can be estimated as residuals (e.g. Marsh et al., 2005) or explicitly (using approaches of Valdivieso Da Costa et al. (2005)). Longer-term experiments with high resolution models for periods of several decades covered by the newest updates of the NCEP/NCAR and ERA-40 reanalyses, may provide information about the characteristics of interannual variability in the surface water mass transformation. Longer-term simulations may quantify the extent to which these characteristics were adequately represented in coarse resolution models (Gulev et al., 2003; Haines and Old, 2005). Of special interest is the analysis of applicability of flux products based on observations (e.g. Josey et al., 1999) for forcing model experiments. Recently Gulev et al. (2007) have shown that time dependent sampling biases in such products may affect the patterns of interannual variability. It would be interesting to quantify the impact of this problem on characteristics of surface water mass transformation.

\section{Acknowledgements}

This work was done during the visits of SKG to LEGI in 2001-2005, funded by Institut National des Sciences de l'Univers du Centre National de la Recherche Scientifique (INSU/CNRS) and the DRAKKAR project. He thanks LEGI for its hospitality. Special thanks to Josianne Brasseur who did her very best supporting our everyday work. Discussions with Bill Large of NCAR (Boulder), Gurvan Madec of LODYC (Paris) and Anne-Marie Treguier of IFREMER (Brest) are greatly appreciated. Suggestions and criticism of two anonymous reviewers helped very much to improve the manuscript. This study was supported by grants from PNEDC program, managed by CNRS/INSU, the CNRS/CNES CLIPPER project, and Russian Ministry of Education and Science under the "World Ocean" Federal Programme, the contract 02.515.11.5032 and 
a special grant NS-7247.2006.5. We acknowledge the support of Institut du Developpement et des Ressources en Informatique Scientifique (IDRIS) in Orsay, where numerical calculations were performed.

\section{References}

Barnier, B., 1998. In: Chassignet, E.P., Verron, J. (Eds.), Forcing the Ocean. Modeling and Parameterization. Kluwer Academic Publishers, The Netherlands, pp. 45-80.

Barnier, B., Siefridt, L., Marchesiello, P., 1995. Thermal forcing for a global ocean circulation model using a three-year climatology of ECMWF analyses. J. Mar. Syst. 6, 363-380.

Barnier, B., Reynaud, T., Beckmann, A., Böning, C., Molines, J.-M., Barnard, S., Jia, Y., 2001. On the seasonal variability and eddies in the North Brazil Current: insights from model intercomparison experiments. Prog. Oceanogr. 48, 195-230.

Barnier, B., Madec, G., Penduff, T., Molines, J.-M., Treguier, A.-M., Le Sommer, J., Beckmann, A., Biastoch, A., Böning, C., Dengg, J., Derval, C., Durand, E., Gulev, S., Remy, E., Talandier, C., Theetten, S., McClean, J., DeCuevas, B., 2006. Impact of partial steps and momentum advection schemes in a global ocean circulation model at eddy-permitting resolution. Ocean Dyn. 56. doi:10.1007/s10236006-0082-1.

Battisti, D.S., Bhatt, U.S., Alexander, M.A., 1995. A modelling study of the interannual variability in the wintertime North Atlantic Ocean. J. Climate 8, 3067-3083.

Beismann, J.O., Barnier, B., 2004. Variability of the meridional overturning circulation of the North atlantic: sensitivity to the overflow of dense water masses. Ocean Dyn. 54 (1), 92-106. doi:10.1007/s10236-003-0088.

Bishop, J.K.B., Rossow, W.B., 1991. Spatial and temporal variability of global surface solar irradiance. J. Geophys. Res. 96, 1683916858.

Böning, C., Bryan, F.O., Holland, W.R., Doesher, R., 1996. Deep water formation and meridional overturning in a high resolution model of the North Atlantic. J. Phys. Oceanogr. 26, 1142-1164.

Böning, C.W., Budich, R.G., 1992. Eddy dynamics in a primitive equation model: sensitivity to horizontal resolution and friction. J. Phys.Oceanogr. 22, 361-381.

Chanut, J., Barnier, B., Large, W., Debreu, L., Penduff, T., Molines, J.M., Mathiot, P., 2007. Mesoscale eddies in the Labrador sea and their contribution to the convection and restratification. J. Phys. Oceanogr., submitted for publication.

Chelton, D.B., deSzoeke, R.A., Schlax, M.G., El Nagar, K., Siwertz, N., 1998. Geographical variability of the first baroclinic Rossby Radius of deformation. J. Phys. Oceanogr. 28, 433-460.

The CLIPPER Team, 2001. 1/6 Atlantic circulation model forced by the ECMWF climatology: preliminary results. PROJET CLIPPER, LEGI - LODYC - LPO, High Resolution modeling of the Atlantic Circulation in forced and coupled mode. Project report, 2001. Grenoble, 141 pp. <http://www-meom.hmg.inpg.fr/Web/Projets/CLIPPER/index.html>.

Crosnier, L., Barnier, B., Tréguier, A.M., 2001. Aliasing of inertial oscillations in the $1 / 6^{\circ}$ Atlantic circulation Clipper model: impact on the mean meridional heat transport. Ocean Modell. 3, 21-32.

da Silva, A.M., Young, C.C., Levitus, S., 1994. Atlas of surface marine data. NOAA Atlas NESDIS 6, Vols. 1-6, US Dept. Commerce, NODC, NOAA/NESDIS, Washington DC.

Eden, C., Willebrand, J., 2001. Mechanism of interannual to decadal variability of the North Atlantic circulation. J. Climate 14, 22662280 .

Ezer, T., 1999. Decadal variabilities of the upper layers of the subtropical North Atlantic: an ocean model study. J. Phys. Oceanogr. 29, 3111-3124.

Fratantoni, D.M., Richardson, P.L., 2006. The evolution and demise of North Brazil Current Rings. J. Phys. Oceanogr. 36, $1241-1264$.

Garnier, E., Barnier, B., Siefridt, L., Beranger, K., 2000. Investigating the 15-year air-sea flux climatology from the ECMWF re-analysis project as surface boundary condition from ocean models. Int. J. Climatol. 20, 1653-1673.

Gent, P.R., McWillams, J.C., 1990. Isopycnal mixing in ocean circulation models. J. Phys. Oceanogr. 20, 150-155.

Griffies, S.M., Böning, C.W., Bryan, F.O., Chassignet, E.P., Gerdes, R., Hasumi, H., Hirst, A., Treguier, A.-M., Webb, D., 2000. Developments in ocean climate modelling. Ocean Modell. 2, 123-192.

Gulev, S.K., Barnier, B., Knochel, H., Molines, J.-M., Cottet, M., 2003. Water mass transformation in the North Atlantic and its impact on the meridional circulation: insights from on ocean model forced by NCEP/NCAR reanalysis surface fluxes. J. Climate 16, 30853110 .

Gulev, S.K., Jung, T., Ruprecht, E., 2007. Estimation of the impact of sampling errors in the VOS observations on air-sea fluxes. Part II. Impact on trends and interannual variability. J. Climate 20, 302-315.

Haidvogel, D.B., Wilkin, J.L., Young, R.E., 1991. A semi-spectral primitive equation ocean circulation model using vertical sigma and orthogonal curvilinear coordinates. J. Comp. Phys. 94, 151-185.

Hakkinen, S., 1999. Variability in the simulated meridional heat transport in the North Atlantic for the period 1951-1993. J. Geophys. Res. 104, 10991-11007.

Hall, N., Barnier, B.B., Penduff, T., Molines, J.M., 2004. Interannual variation of Gulf Stream heat transport in a high resolution model forced by reanalysis data. Climate Dyn. 23, 341-351.

Halliwell, G.R., 1998. Simulation of North Atlantic decadal/multidecadal winter SST anomalies driven by basin scale atmospheric circulation anomalies. J. Phys. Oceanogr. 28, 5-21.

Haney, R.L., 1971. Surface thermal boundary condition for ocean circulation models. J. Phys. Oceanogr. 1, $145-167$.

Haines, K., Old, C., 2005. Diagnosing natural variability of North Atlantic water masses in HadCM3. J. Climate 18, $1925-1941$. 
Jackett, D.R., McDougall, T.J., 1995. Minimal adjustment of hydrographic profiles to achieve static stability. J. Atmosph. Ocean. Tech. 12, 381-389.

Josey, S., Kent, E.K., Taylor, P.K., 1999. New insights into the ocean heat budget closure problem from analysis of the SOC air-sea flux climatology. J. Climate 12, 2856-2880.

Krahmann, G., Visbeck, M., Reverdin, G., 2001. Formation and propagation of temperature anomalies along the North Atlantic Current. J. Phys Oceanogr. 31, 1287-1303.

Kalnay, E., Kanamitsu, M., Kistler, R., Collins, W., Deaven, D., Gandin, L., Iredell, M., Saha, S., White, G., Woollen, J., Zhu, Y., Chelliah, M., Ebisuzaki, W., Higgis, W., Janowiak, J., Mo, K.C., Ropelewski, C., Wang, J., Leetmaa, A., Reynolds, R., Jenne, R., Joseph, D., 1996. The NCEP/NCAR 40-year reanalysis project. Bull. Am. Meteorol. Soc. 77, 437-471.

Kistler, R., Kalnay, E., Collins, W., Saha, S., White, G., Woolen, J., Chelliah, M., Ebisuzaki, W., Kanamitsu, M., Kousky, V., van den Dool, H., Jenne, R., Fiorino, M., 2001. The NCEP/NCAr 50-year reanalysis, monthly means CD-ROM and documentation. Bull. Am. Meteorol. Soc. 82, 247-267.

Ladd, C., Thompson, L., 2001. Water mass formation in an isopycnal model of the North Pacific. J. Phys. Oceanogr. $31,1517-1537$.

Large, W.G., Danabasoglu, G., Doney, S.C., 1997. Sensitivity to surface forcing and boundary layer mixing in a global ocean model: annual-mean climatology. J. Phys. Oceanogr. 27, 2418-2446.

Large, W.G., Nurser, A.J.G., 2001. Ocean surface water mass transformation. In: Siedler, G., Church, J., Gould, J. (Eds.), Ocean Circulation and Climate. Academic Press, pp. 317-336.

Levitus, S., 1982. Climatological Atlas of the World Ocean. NOAA Professional Paper 13, Washington DC, 173 pp.

Madec, G., Delecluse, P., Imbard, M., Levy, C., 1998. OPA 8.1 General Circulation Model reference manual, Notes de l'IPSL. Université P. et M. Curie, Paris, France, p. 91.

Marsh, R., 2000. Recent variability of the North Atlantic thermohaline circulation inferred from surface heat and fresh water fluxes. J. Climate 13, 3239-3260.

Marsh, R., Josey, S.A., Nurser, A.J.G., de Cuevas, B.A., Coward, A.C., 2005. Water mass transformation in the North Atlantic over 1985-2002 simulated in an eddy-permitting model. Ocean Sci. 1, 127-144.

Marshall, J., Jamous, D., Nilsson, J., 1999. Reconciling thermodynamic and dynamic methods of computation of water-mass transformation rates. Deep-Sea Res. 46, 545-572.

McWilliams, J.C., Danabasoglu, G., 2002. Eulerian and eddy-induced meridional overturning circulations in the tropics. J. Phys. Oceanogr. 32, 2054-2071.

Nurser, A.J.G., Marsh, R., Williams, R.G., 1999. Diagnosing water mass formation from air-sea fluxes and surface mixing. J. Phys. Oceanogr. 29, 1468-1487.

Penduff, T., Barnier, B., Dewar, W.K., O’Brien, J.J., 2004. Dynamical response of the oceanic eddy field to the north Atlantic oscillation: a model-data comparison. J. Phys. Oceanogr. 34 (12), 2615-2629.

Penduff, T., Barnier, B., Molines, J.-M., Madec, G., 2005. On the use of current meter data to assess the realism of ocean model simulations. Ocean Modell. 11 (3-4), 399-416.

Reynaud, T., Legrand, P., Mercier, H., Barnier, B., 1998. A new analysis of hydrographic data in the Atlantic and its application to an inverse modelling study. International WOCE Newsletter, No. 32, WOCE International Project Office, Southampton, United Kingdom, pp. 29-31.

Reynolds, R.W., Smith, T.M., 1994. Improved global sea surface temperature analyses using optimum interpolation. J. Climate 7, 929948.

Schmitt, R.W., Bogden, P.S., Dorman, C.E., 1989. Evaporation minus precipitation and density fluxes for the North Atlantic. J. Phys. Oceanogr. 19, 1208-1221.

Speer, K., 1993. Conversion among North Atlantic surface water types. Tellus 45A, 72-79.

Speer, K., Tziperman, E., 1992. Rates if water mass formation in the North Atlantic Ocean. J. Phys. Oceanogr. $22,93-104$.

Speer, K., Isemer, H.-J., Biastoch, A., 1995. Water mass formation from revised COADS data. J. Phys. Oceanogr. $25,2444-2457$.

Straneo, F., 2006. On the connection between dense water formation, overturning, and poleward heat transport in a convective basin. J. Phys. Oceanogr. 36, 1822-1840.

Tréguier, A.M., de Miranda, B.BarnierA., Molines, J.M., Grima, N., Imbard, M., Madec, G., Messager, C., Michel, S., 2001. An eddy permitting model of the Atlantic circulation: evaluating open boundary conditions. J. Geophys. Res. 106, $22115-22129$.

Treguier, A.M., Boebel, O., Barnier, B., Madec, G., 2003. Agulhas eddy fluxes in a 1/6 Atlantic model. Deep-Sea Res. 50B, 251-280.

Tziperman, E., 1986. On the role of interior mixing and air-sea fluxes in determining the stratification and circulation of the oceans. J. Phys. Oceanogr. 16, 680-693.

Uppala, S., Kallberg, P.W., Simmons, A.J., Andrae, U., Da Costa Bechtold, V., Fiorino, M., Gibson, J.K., Haseler, J., Hernandez, A., Kelly, G.A., Li, X., Onogi, K., Saarinen, S., Sokka, N., Allan, R.P., Andersson, E., Arpe, K., Balmaseda, M.A., Beljaars, A.C.M., van de Berg, L., Bidlot, J., Bormann, N., Caires, S., Chevallier, F., Dethof, A., Dragosavac, M., Fisher, M., Fuentes, M., Hagemann, S., Holm, E., Hoskins, B.J., Isaksen, L., Janssen, P.A.E.M., Jenne, R., McNally, A.P., Mahfouf, J.-F., Morcrette, J.-J., Rayner, N.A., Saunders, R.W., Simon, P., Sterl, A., Trenberth, K.E., Untch, A., Vasiljevic, D., Viterbo, P., Woollen, J., 2005. The ERA-40 reanalysis. Q. J. R. Meteorol. Soc. 131, 2961-3012.

Valdivieso Da Costa, M.V., Mercier, H., Treguier, A.M., 2005. Effects of the mixed layer time variability on kinematic subduction rate diagnostics. J. Phys. Oceanogr. 35, 427-443.

Visbeck, M., Cullen, H., Krahmann, G., Naik, N., 1998. An ocean model response to the North Atlantic Oscillation - like wind forcing. Geophys. Res. Lett. 25, 4521-4524.

Walin, G., 1982. On the relation between sea-surface heat flow and thermal circulation in the ocean. Tellus 34, 187-195. 
The WGASF Group, 2000. Intercomparison and validation of ocean-atmosphere energy flux fields. In: Taylor, P.K. (Ed.), Final Report of the Joint WCRP/SCOR Working Group on Air-Sea Fluxes, WMO, Geneva, Switzerland 305 pp. <http://www.soc.soton.ac.uk/JRD/ MET/WGASF $>$.

Willebrand, J., Barnier, B., Böning, C., Dieterich, C., Killworth, P., LeProvost, C., Yia, J., -M Molines, J., New, A.L., 2001. Circulation characteristics in three eddy-permitting models of the North Atlantic. Prog. Oceanogr. 48, 123-161. 